\title{
Can unstable angina pectoris be due to increased coronary vasomotor tone?
}

\author{
P. W. Serruys, R. Steward, F. Booman, R. Michels, J. H. C. Reiber and P. G. Hugenholtz \\ Thoraxcenter, Erasmus University, Rotterdam, The Netherlands
}

KEY WORDS: Unstable angina pectoris, nifedipine, coronary vasomotion, quantitative angiography.

In this study it is argued that the clinical manifestations of unstable angina pectoris, with at its extreme end impending myocardial infarction, may be due to increased coronary arterial vasomotion superimposed on a pre-existing obstruction in a coronary artery.

As nifedipine, a powerful calcium antagonist, has initially proven its efficacy in relieving the symptoms of Prinzmetal's angina, a condition in which severe spasm of the coronary artery is now proven to be the main cause, the drug was given to two groups of patients in whom abnormal vasomotion was suspected and its effects scrutinized.

Twelve patients with symptoms of coronary artery disease (CAD) were studied with repeated arteriograms after injection of $0 \cdot 15 \mathrm{mg}$ nifedipine in the left coronary artery. Two control cine-angiograms were made prior to drug administration and two cinefilms were repeated $30 \mathrm{~s}$ and $5 \mathrm{~min}$ after administration of nifedipine. The mean diameter of the normal, stenotic and poststenotic segments showed a statistically significant increase after drug administration. Vasodilation persisted after coronary $\mathrm{O}_{2}$ saturation, and presumably coronary flow, had returned to normal.

In 52 other patients, who were seen in the coronary care unit for impending myocardial infarction and who had been treated with maximal beta-adrenergic blockade, nitrates and bedrest, but who remained symptomatic, nifedipine $60 \mathrm{mg}$ orally for $24 \mathrm{~h}$ was added to the treatment. Within $2 \mathrm{~h}$ after administration 42 of the 52 became asymptomatic. In the 10 non-responders, all with extensive multi-vessel disease, two sustained a myocardial infarction and eight received urgent coronary artery bypass grafting in an effort to alleviate their symptoms. All had severe 3 vessel disease in contrast to the responders in whom 1 or 2 vessel disease was predominant.

These data show that increased coronary artery vasomotion can be influenced by nifedipine. The excellent clinical response to the drug in this group of patients with unstable angina pectoris indicates that nifedipine may become the preferred agent to be used particularly when the cause of the angina pectoris is suspected to be the result of abnormal coronary vasomotor tone.

Several studies in the literature ${ }^{[1-10]}$ suggest that major coronary arteries can, under physiological conditions, approximately double their luminal diameter from their most constricted to their most dilated state. If, in contrast, a similar degree of vasoconstriction occurs around an already pre-existing fixed obstruction, a critical reduction in flow may take place which, under certain circumstances, will lead to irreversible ischemia. It then can be understood how the clinical manifestations of unstable angina and impending infarction may follow excessive coronary arterial vasomotion superimposed on an organically narrowed

Received for publication 22 September 1980.

Requests for reprints to: $\mathrm{Dr} \mathrm{P}$. W. Serruys, Catheterization Laboratory, P.B. 1738, Erasmus University, Rotterdam, The Netherlands. vessel. If this hypothesis is correct, it opens up new avenues of treatment, for if there was a truly long acting coronary vasodilator, then the process of impending infarction could be reversed in time and the patient returned to a more stable, or even asymptomatic, state. Nifedipine, a powerful calcium channel blocking agent, provides such vascular dilatation and its efficacy has been proved by many authors in the classical syndrome of Prinzmetal's angina ${ }^{[11-13]}$, where complete spasm of the vascular wall has been shown.

Recently Previtali and coworkers ${ }^{[14]}$ also reported a high degree of efficacy of nifedipine in patients with angina at rest where other causes were suspected. It is generally assumed that the effectiveness of nifedipine in angina at rest is mainly related to its pronounced 
Table 1 Clinical and hemodynamic features of the study group

\begin{tabular}{|c|c|c|c|c|c|c|c|}
\hline & Age & Sex & $\begin{array}{l}\text { NYHA } \\
\text { classification }\end{array}$ & $\begin{array}{l}\text { Coronary } \\
\text { angiogram }\end{array}$ & $\begin{array}{l}\text { Ejection } \\
\text { fraction }\end{array}$ & $\begin{array}{l}\text { EDV } \\
\left(\mathrm{ml} / \mathrm{m}^{2}\right)\end{array}$ & $\begin{array}{l}\text { Infarct } \\
\text { location }\end{array}$ \\
\hline 1. & 55 & $\hat{\jmath}$ & II & normal & 0.67 & 107 & \\
\hline 2. & 56 & $\hat{3}$ & II & $\begin{array}{l}\text { three vessel } \\
\text { disease }\end{array}$ & $0 \cdot 60$ & 66 & \\
\hline 3. & 33 & $\hat{\jmath}$ & II & $\begin{array}{l}\text { three vessel } \\
\text { disease }\end{array}$ & $0 \cdot 65$ & 85 & \\
\hline 4. & 59 & $\hat{\sigma}$ & II & $\begin{array}{l}\text { single vessel } \\
\text { disease }\end{array}$ & $0 \cdot 60$ & 62 & anterior \\
\hline 5. & 47 & $\hat{3}$ & III & $\begin{array}{l}\text { two vessel } \\
\text { disease }\end{array}$ & $0 \cdot 58$ & 98 & anterior \\
\hline 6. & 49 & $\hat{\jmath}$ & II & normal & - & - & \\
\hline 7. & 36 & $\hat{3}$ & III & $\begin{array}{l}\text { three vessel } \\
\text { disease }\end{array}$ & $0 \cdot 25$ & 134 & anterior \\
\hline 8. & 58 & $\hat{\jmath}$ & II & $\begin{array}{l}\text { two vessel } \\
\text { disease }\end{array}$ & $0 \cdot 32$ & 91 & anterior \\
\hline 9. & 55 & ô & III & $\begin{array}{l}\text { two vessel } \\
\text { disease }\end{array}$ & $0 \cdot 67$ & 51 & \\
\hline 10. & 54 & $\hat{\jmath}$ & II & $\begin{array}{l}\text { two vessel } \\
\text { disease }\end{array}$ & 0.68 & 46 & \\
\hline 11. & 53 & $\hat{\sigma}$ & I & $\begin{array}{l}\text { two vessel } \\
\text { disease }\end{array}$ & $0 \cdot 61$ & 83 & \\
\hline 12. & 45 & 3 & III & $\begin{array}{l}\text { three vessel } \\
\text { disease }\end{array}$ & $0 \cdot 61$ & 51 & \\
\hline
\end{tabular}

Abbreviation: $\mathrm{EDV}=$ end-diastolic volume.

afterload reduction and to its direct blocking effect on the excitation-coupling mechanism inside the cardiac cells. However, efficacy may also be related to its capacity to decrease the calcium-dependent contractile tone of the cells in the epicardial coronary arterial wall ${ }^{[15,16]}$. By reducing this tone these cells appear less sensitive to vasoconstricting stimuli, as indicated elsewhere in this symposium.

In order to unravel these often coincident actions, the effects of an intracoronary injection of nifedipine on coronary vasomotility and left ventricular hemodynamics were investigated in 12 patients with suspected coronary artery disease. Subsequently, the drug was also given to a group of 52 patients with unstable angina, whose pain persisted at rest, with continued ST-T wave changes, although therapy had been given over $8 \mathrm{~h}$ consisting of maximal beta-adrenergic blockade, nitrates (some intravenously) and bedrest.

\section{Material and methods}

For the first part of the study, data were collected from 12 patients catheterized for suspected coronary artery disease. Their clinical and hemodynamic data are summarized in Table 1. Two patients had normal coronary arteries, there was one patient with one vessel disease, six patients had two vessels obstructed, three patients had three vessel obstruction, all of $70^{\circ}$ or more. The effects of an intracoronary injection of nifedipine on coronary vasomotility were studied in four consecutive coronary cine-angiograms. Before the angiographic study, a fiberoptic catheter* was inserted into the coronary sinus and the $\mathrm{O}_{2}$ saturation continuously measured ${ }^{[17]}$. The left ventricular pressure was continuously recorded with a tipmanometer (Millar PC 471 or 481 , PC 770 or $880 \dagger$ ) and analyzed for changes in left ventricular contractility, reflected by peak $\mathrm{dP} / \mathrm{dt}$, peak $\mathrm{VCE}$ and $\mathrm{V}_{\max }{ }^{[18,19]}$.

A total of 41 segments were selected for quantitative angiographic analysis. Eight were stenotic in nature, 22 were poststenotic, and 11 were normal. Before the pharmacological intervention, two baseline coronary angiograms were performed with a $5 \mathrm{~min}$ interval. The second control angiogram was carried out to study the effect of the contrast agent itself on the artery.

Five minutes later, $0.15 \mathrm{mg}$ of nifedipine was injected within $20 \mathrm{~s}$, into the left main coronary artery $\mathrm{y}^{[20]}$, and an arteriogram was repeated as soon as the coronary sinus saturation reached its maximum value, usually within $30 \mathrm{~s}$. The final coronary angiogram was obtained as soon as the coronary sinus saturation had returned to its control values, usually within $5 \mathrm{~min}$.

All arteriograms were obtained via the Sones technic and recorded on Kodak $35 \mathrm{~mm}$ cinefilm (RAR

* American Optical Company, Southbridge, Massachusetts, U.S.A. † Millar Instruments Inc., Houston, Texas, U.S.A. 


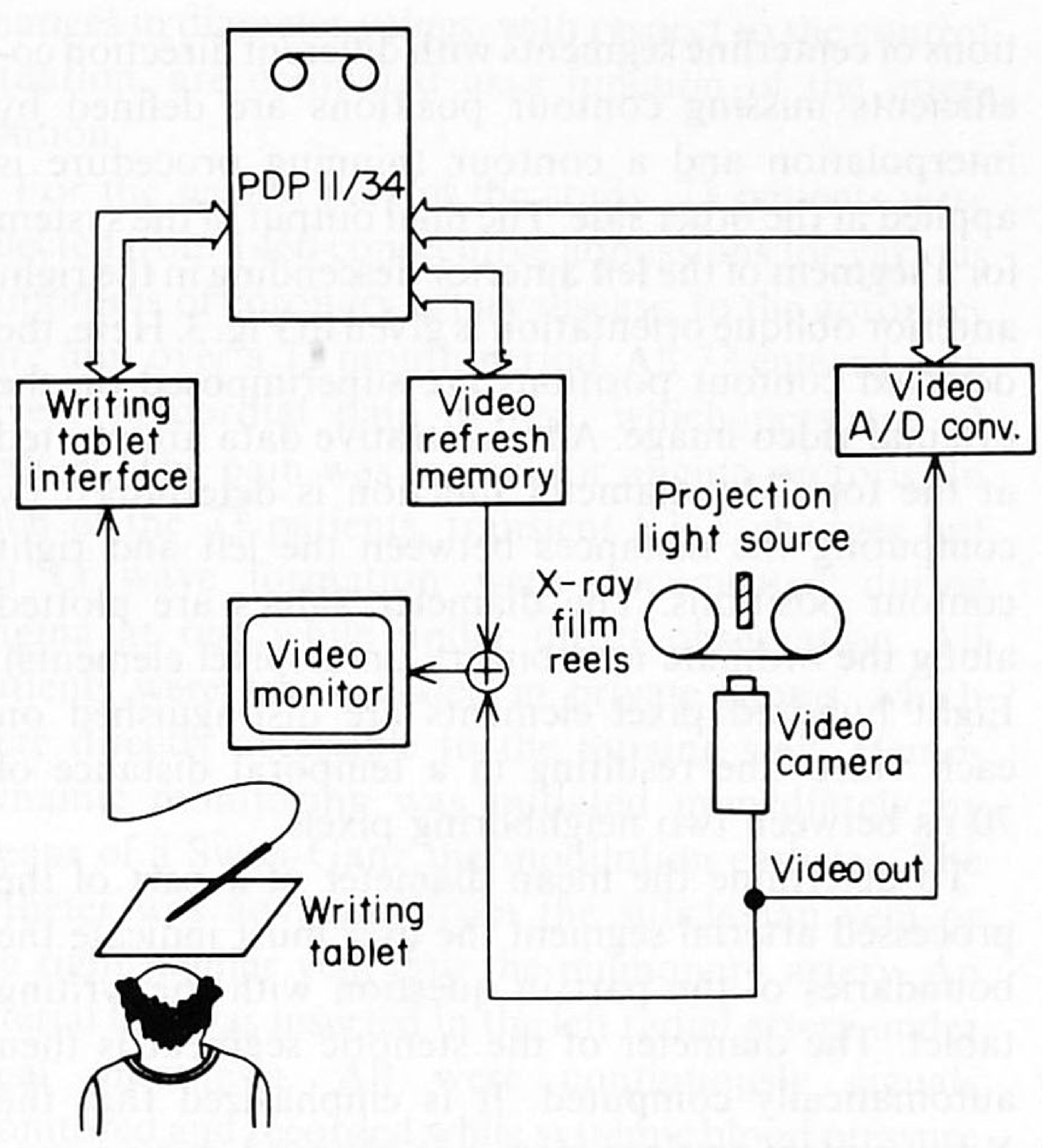

Figure 1 Block diagram of the coronary angiography analysis system.

(a)

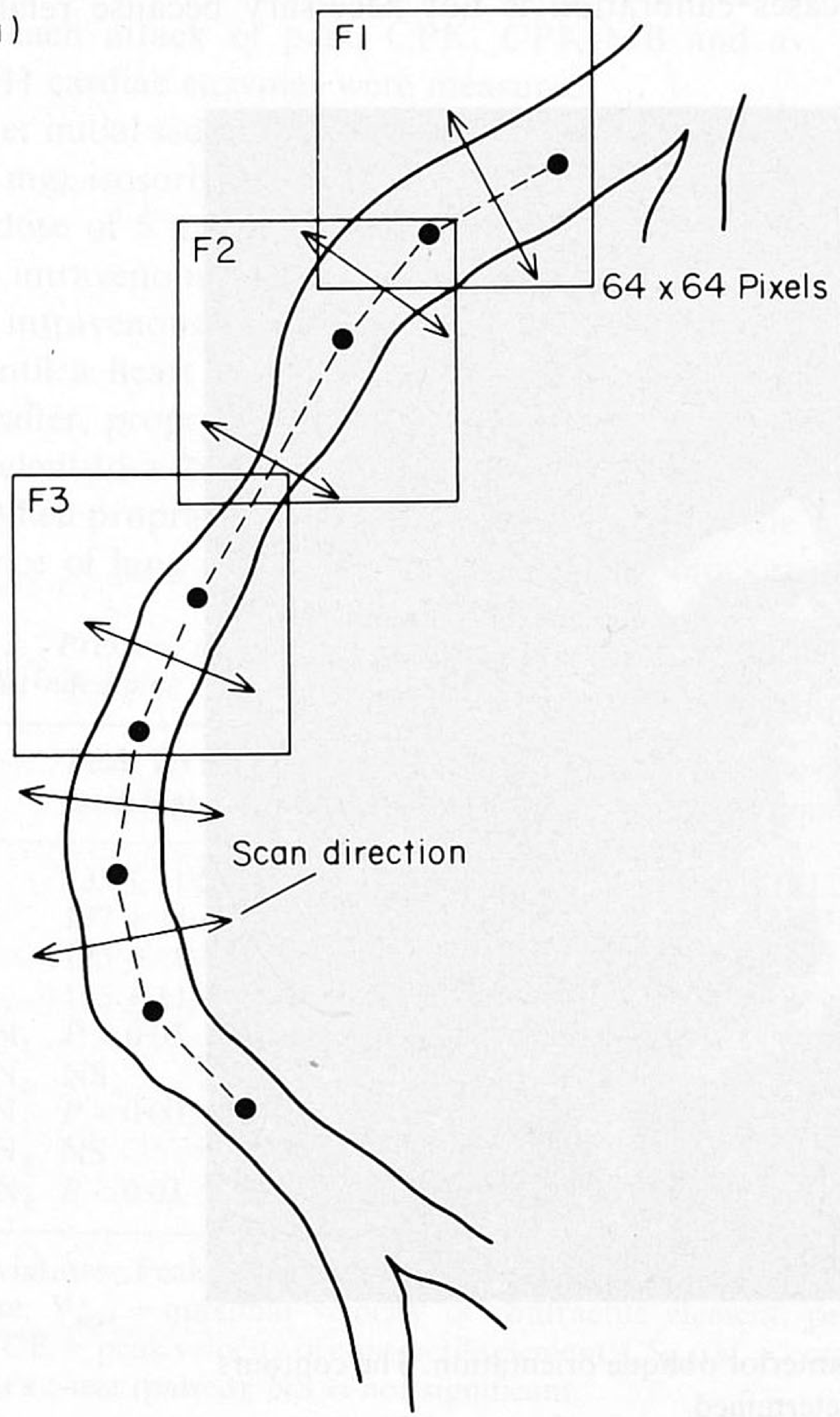

(b)

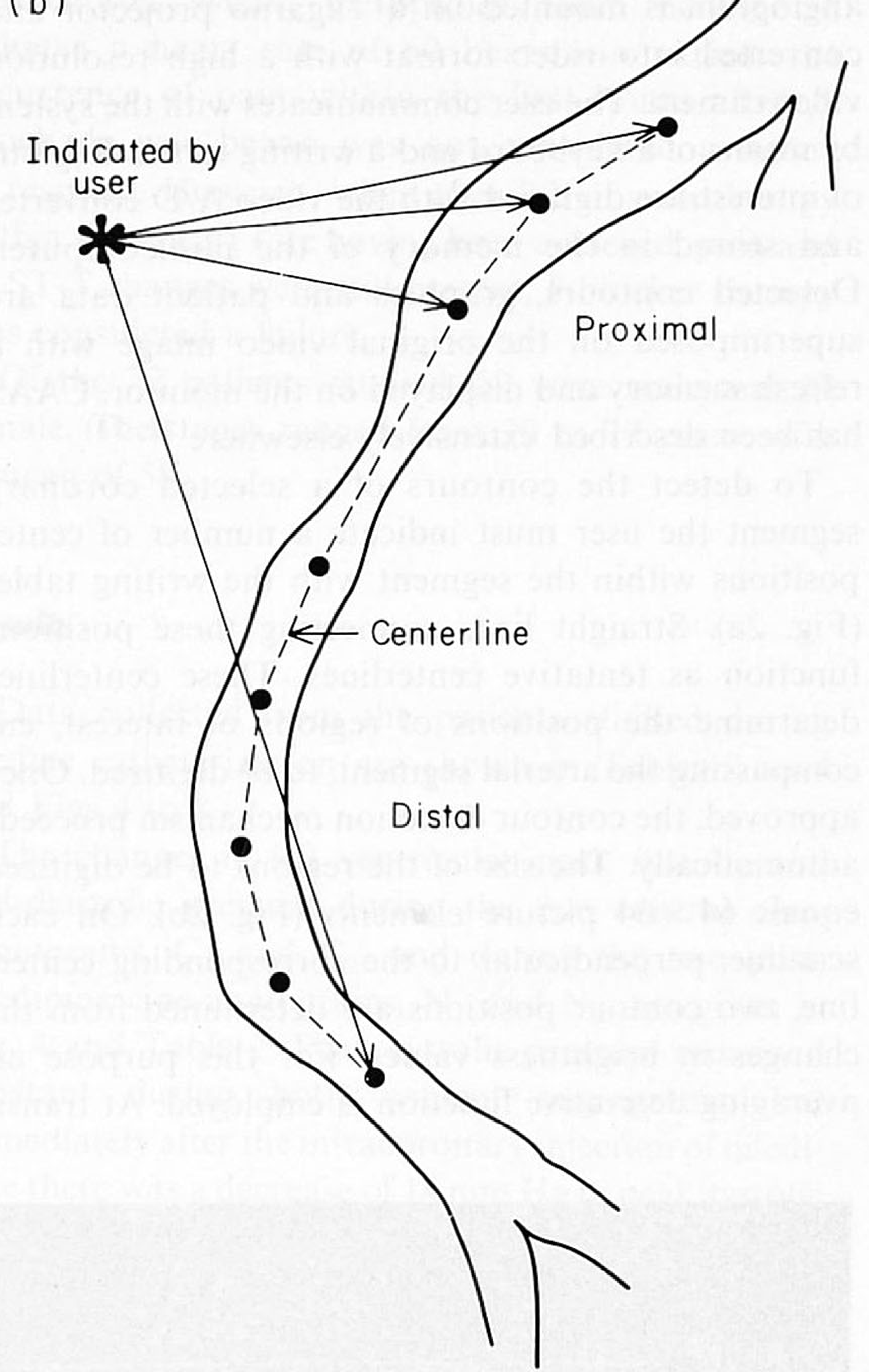

Figure 2 (a) To analyze a selected coronary artery lesion the user indicates a number of center positions. These inter-polated straight lines function as a tentative centerline. (b) For the schematic drawing of Fig. 2a the scan directions perpendicular to the corresponding centerline segments are given as well as the positions of the $64 \times 64$ matrices to be digitized.

film 2496) at the rate of 50 frames per s with the biplane Cardioskope U (Siemens*). As for the contrast medium, Urografin $76 \%$ (Schering $\dagger$ ) was injected at a flow rate of $3 \mathrm{ml} / \mathrm{s}$ with a Medrad injector (Mark IV) + .

\section{CORONARY ANGIOGRAPHY ANALYSIS SYSTEM}

The quantitative analysis of selected coronary segments was carried out with the help of a computer based Coronary Angiography Analysis System (CAAS), of which a block diagram is shown in Fig. 1. The central processor is a PDP 11/34 mini computer with $32 \mathrm{k}$ words of memory. A $35 \mathrm{~mm}$ frame of a cine-

* Siemens AG, Henkestrasse, Erlangen, G.B.R.

† Schering AG, Berlin, Bergkammen, G.B.R.

$\ddagger$ Medrad Inc., Pittsburgh, Pennsylvania, U.S.A. 
angiogram is mounted on a Tagarno projector and converted into video format with a high resolution video camera. The user communicates with the system by means of a keyboard and a writing tablet. Regions of interest are digitized with the video A/D converter and stored in the memory of the minicomputer. Detected contours, graphics and patient data are superimposed on the original video image with a refresh memory and displayed on the monitor. CAAS has been described extensively elsewhere ${ }^{[21-23]}$.

To detect the contours of a selected coronary segment the user must indicate a number of center positions within the segment with the writing tablet (Fig. 2a). Straight lines connecting these positions function as tentative centerlines. These centerlines determine the positions of regions of interest, encompassing the arterial segment, to be digitized. Once approved, the contour detection mechanism proceeds automatically. The size of the regions to be digitized equals $64 \times 64$ picture elements (Fig. 2b). On each scanline, perpendicular to the corresponding centerline, two contour positions are determined from the changes in brightness values. For this purpose an averaging derivative function is employed. At transi- tions of centerline segments with different direction coefficients missing contour positions are defined by interpolation and a contour thinning procedure is applied at the other side. The final output of the system for a segment of the left anterior descending in the right anterior oblique orientation is given in Fig. 3. Here, the detected contour positions are superimposed on the original video image. Administrative data are plotted at the top. The diameter function is determined by computing the distances between the left and right contour positions. The diameter values are plotted along the ordinate in arbitrary units (pixel elements). Eight hundred pixel elements are distinguished on each video line resulting in a temporal distance of 70 ns between two neighboring pixels.

To determine the mean diameter of a part of the processed arterial segment the user must indicate the boundaries of the part in question with the writing tablet. The diameter of the stenotic segment is then automatically computed. It is emphasized that the $\mathrm{X}$-ray system settings were not changed during consecutive filming after drug injection in order to hold the orientation and magnification constant. In these cases calibration is not necessary because relative

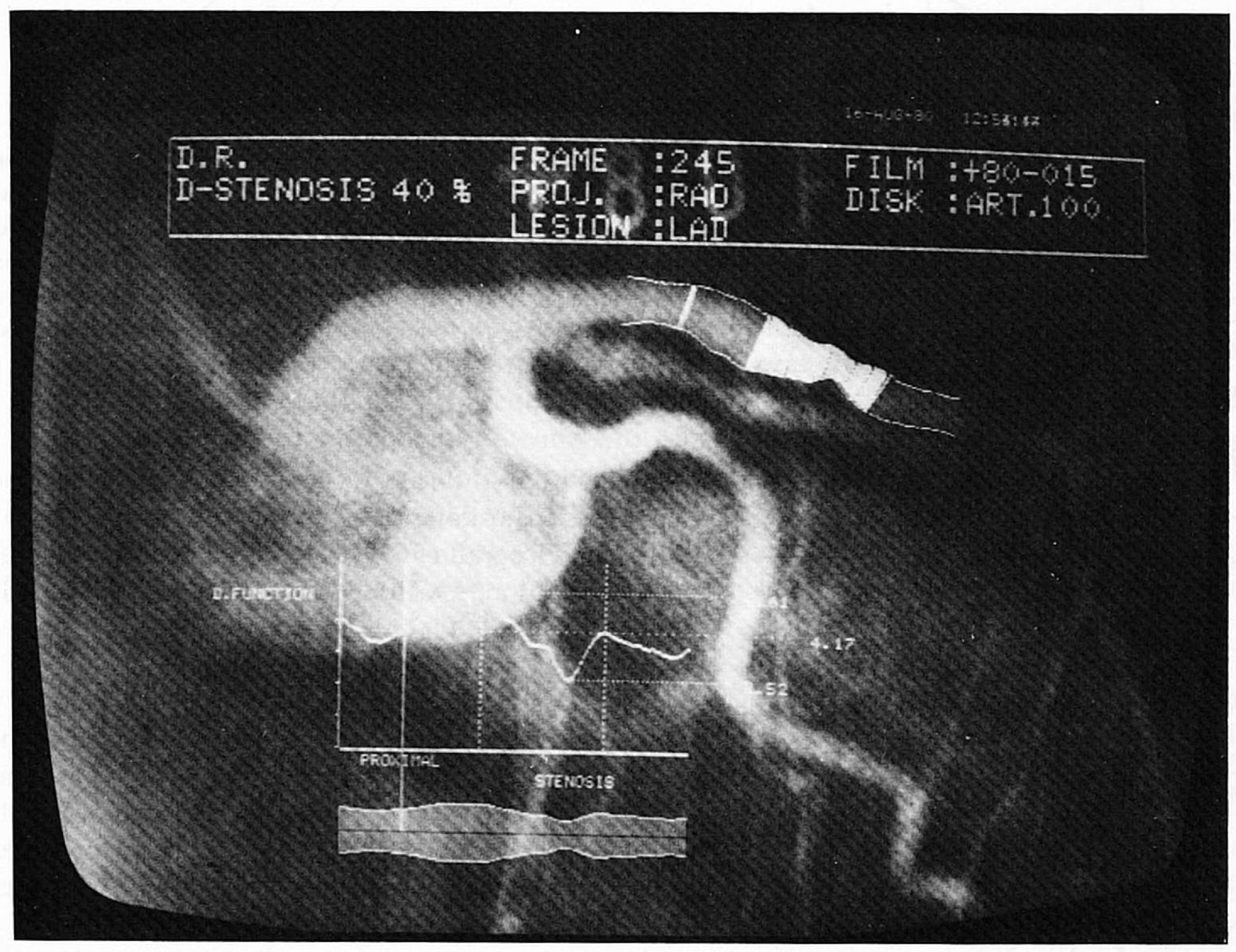

Figure 3 Computer output of the measured lesion in the right anterior oblique orientation. The contours have been detected; from these data the diameter function is determined. 
changes in diameter values, with respect to the control situation, are computed as a function of the intervention.

For the second part of the study, 73 patients were selected from 1460 consecutive admissions for various symptoms of coronary artery disease, to the coronary care unit over a 12 month period. All 73 entered with severe precordial pain at rest, which persisted at bedrest. The pain was typical for angina pectoris. In each of the 73 patients, transient ST-T changes but no $\mathrm{Q}$ wave formation were documented during angina at rest while under direct observation. All patients were semi-isolated in private rooms, which were directly accessible to the nursing staff. Hemodynamic monitoring was initiated immediately by means of a Swan-Ganz thermodilution catheter. The catheter was advanced from the subclavian vein or the right jugular vein into the pulmonary artery. An arterial line was inserted in the left radial artery under local anesthesia. All were continuously signals monitored and recorded while systemic blood pressure and cardiac output were determined at regular intervals. During and following each attack of pain, a 12-lead ECG was recorded. Upon admission and $6 \mathrm{~h}$ after each attack of pain, CPK, CPK-MB and $\alpha$ $\mathrm{HBDH}$ cardiac enzymes were measured.

After initial sedation, usually with oral diazepam (5 to $10 \mathrm{mg}$ ), isosorbide dinitrate was given sublingually in a dose of $5 \mathrm{mg}$ every $2 \mathrm{~h}$, or if necessary, it was given intravenously. Also, propranolol was administered intravenously at dosages varying from 1 to 10 mg until a heart rate of 60 beats/min was reached. Thereafter, propranolol was given orally at dosages equivalent to a $24 \mathrm{~h}$ dosage of between 400 and 800 mg. When propranolol was contraindicated, as in the presence of lung disease, a cardioselective $\beta$-blocker was chosen, usually metoprolol. Since the time to achieve a heart rate of 60 beats/min varied, the recurrence of pain within the first hours after $\beta$ blockade was begun was not considered a failure to respond. However, when after $8 \mathrm{~h}$ of such therapy with a slow heart rate having been achieved, pain and or ST-T changes were still present, $\beta$-blocker therapy was considered a failure.

Of the 73 patients studied, 59 were male and 14 female. Their ages ranged from 29 to 77 years, with a mean of 58 .

\section{Results}

Data collected from the patients studied during cardiac catheterization are shown in Tables 2 to 4 and Figs 4 to 8.

The changes in left ventricular peak systolic and end-diastolic pressure during the two control cineangiograms. $\mathrm{C}_{1}$ and $\mathrm{C}_{2}$, and during the two postnifedipine cine-angiograms, $\mathrm{N}_{1}$ and $\mathrm{N}_{2}$, are given in Fig. 4 and Table 2. Peak systolic pressure remained constant during both control angiograms, but immediately after the intracoronary injection of nifedipine there was a decrease of $14 \mathrm{~mm} \mathrm{Hg}$ in peak systolic pressure $(P<0.05)$. This acute change was transient and followed by return to control values, within 5 min - so that by the time of the fourth coronary angiogram, the LV pressure had returned to its control value of $135 \mathrm{~mm} \mathrm{Hg}$. End-diastolic pressure showed a significant increase $(P<0.01)$ from 19 to $25 \mathrm{~mm} \mathrm{Hg} 30 \mathrm{~s}$ after the intracoronary injection. During the fourth cinefilm, the end-diastolic pressure was still slightly, but not significantly, elevated.

After the intracoronary injection of nifedipine peak

Table 2 Pressure derived variables and coronary sinus saturation during the two control $\left(C_{1}, C_{2}\right)$ and the two post-nifedipine cine-angiograms $\left(N_{1}, N_{2}\right)$. (Mean \pm s.e.m)

\begin{tabular}{|c|c|c|c|c|c|c|}
\hline & $\begin{array}{l}\text { Peak LVSP } \\
(\mathrm{mm} \mathrm{Hg})\end{array}$ & $\begin{array}{l}\text { LVEDP } \\
(\mathrm{mm} \mathrm{Hg})\end{array}$ & $\begin{array}{l}V_{\text {max }} \\
\left(s^{-1}\right)\end{array}$ & $\begin{array}{l}\text { Peak } \mathrm{dP} / \mathrm{dt} \\
\left(\mathrm{mm} \mathrm{Hg} \mathrm{s}^{-1}\right)\end{array}$ & $\begin{array}{l}\text { Peak VCE } \\
\left(\mathrm{s}^{-1}\right)\end{array}$ & $\mathrm{CS}_{\mathrm{O} 2}$ sat \\
\hline$C_{1}$ & $135 \pm 11 \cdot 5$ & $18 \pm 2 \cdot 6$ & $47 \cdot 8 \pm 2 \cdot 3$ & $1722 \pm 191$ & $35 \cdot 5 \pm 3 \cdot 8$ & $36 \pm 3 \cdot 0$ \\
\hline $\mathrm{C}_{2}$ & $137 \pm 11 \cdot 6$ & $19 \pm 2 \cdot 6$ & $45 \pm 2 \cdot 10$ & $1607 \pm 120$ & $32 \pm 2 \cdot 5$ & $\pm 3 \cdot 2$ \\
\hline$N_{1}$ & $123 \pm 8 \cdot 4$ & $25 \pm 3 \cdot 1$ & $36.7 \pm 2.8$ & $1333 \pm 139$ & $24 \cdot 3 \pm 2 \cdot 4$ & $63 \pm 4.7$ \\
\hline $\mathrm{N}_{2}$ & $135 \pm 11$ & $22 \pm 2 \cdot 6$ & $47.5 \pm 1.9$ & $1629 \pm 139$ & $31 \cdot 3 \pm 2 \cdot 6$ & $35 \cdot 3 \pm 1 \cdot 1$ \\
\hline $\mathrm{C}_{1} v \cdot \mathrm{N}_{1}$ & $P<0.05$ & $P<0.002$ & $P<0.005$ & $P<0.02$ & $P<0.02$ & $P<\overline{0.01}$ \\
\hline$C_{1} v \cdot \mathrm{N}_{2}$ & NS & NS & NS & NS & NS & NS \\
\hline $\mathrm{C}_{2} v \cdot \mathrm{N}_{1}$ & $P<0.005$ & $P<0.001$ & $P<0.002$ & $P<0.05$ & $P<0.01$ & $P<0.005$ \\
\hline $\mathrm{C}_{2} v \cdot \mathrm{N}_{2}$ & NS & NS & NS & NS & NS & NS \\
\hline $\mathrm{N}_{1}$ v. $\mathrm{N}_{2}$ & $P<0.03$ & NS & $P<0.002$ & $P<0.02$ & $P<0.01$ & $P<0.005$ \\
\hline
\end{tabular}

Abbreviations: Peak LVSP = peak left ventricle systolic pressure; LVEDP = left ventricle end-diastolic pressure; $\mathrm{V}_{\max }=$ maximal velocity of contractile element; peak $\mathrm{dP} / \mathrm{dt}=$ first derivative $\mathrm{LV}$ pressure; peak $\mathrm{VCE}=$ peak velocity of contractile element $\mathrm{CS}_{\mathrm{O} 2}$ sat $=$ coronary sinus oxygen saturation; $P=P$ value Student's t-test (paired); NS = not significant. 
Table 3 Mean diameter values, expressed in pixels (picture element), during the two control $\left(C_{1}, C_{2}\right)$ and the two postnifedipine $\left(N_{1}, N_{2}\right)$ cine-angiograms

\begin{tabular}{|c|c|c|}
\hline & $\begin{array}{l}\text { Mean diameter of } \\
\text { normal segments } \\
(\mathrm{n}=11)\end{array}$ & $\begin{array}{l}\text { Mean diameter of } \\
\text { poststenotic } \\
\text { segments }(n=21)\end{array}$ \\
\hline & mean \pm s.e.m. & mean \pm s.e.m. \\
\hline$C_{1}$ & $19.86 \pm 1.69$ & $17 \cdot 42 \pm 0.76$ \\
\hline $\mathrm{C}_{2}$ & $20 \cdot 32 \pm 1.89$ & $17 \cdot 25 \pm 0 \cdot 80$ \\
\hline$N_{1}^{2}$ & $20.53 \pm \cdot 1.81$ & $18.34 \pm 0.67$ \\
\hline $\mathrm{N}_{2}$ & $22.07 \pm 1.99$ & $19.50 \pm 0.76$ \\
\hline$C_{1} v \cdot C_{2}$ & NS & NS \\
\hline $\mathrm{C}_{1} v \cdot \mathrm{N}_{2}$ & $P<0.005$ & $P<5 \cdot 10^{-6}$ \\
\hline $\mathrm{C}_{2} v \cdot \mathrm{N}_{1}$ & NS & $P<0.02$ \\
\hline $\mathrm{C}_{2} v \cdot \mathrm{N}_{2}$ & $P<0.01$ & $P<5 \cdot 10^{-7}$ \\
\hline $\mathrm{N}_{1} v \cdot \mathrm{N}_{2}$ & $P<0.0005$ & $P<0.005$ \\
\hline
\end{tabular}

Abbreviations: $P=P$ value, paired t-test of Student; $N S=$ not significant.

Table 4 Luminal diameters of eight stenotic lesions during the control cine-angiogram $(C)$ and after $(N)$ intracoronary administration of nifedipine; luminal diameters are expressed in pixels. Luminal diameter change is defined as: $(N-C) / C$ $\times 100$, and expressed as a percentage

\begin{tabular}{lll}
\hline $\begin{array}{l}\text { Control } \\
\text { (C) }\end{array}$ & $\begin{array}{l}\text { Nifedipine } \\
(\mathrm{N})\end{array}$ & $\begin{array}{l}\text { Luminal } \\
\text { diameter change } \\
(\%)\end{array}$ \\
\hline 4.73 & 6.18 & 31 \\
9.92 & 12.59 & 27 \\
10.93 & 13.67 & 25 \\
10.31 & 12.63 & 22.5 \\
13.75 & 16.10 & 17 \\
13.97 & 15.29 & 9.4 \\
8.32 & 8.68 & 4.3 \\
9.84 & 8.90 & -9.5 \\
\hline
\end{tabular}

$\mathrm{dP} / \mathrm{dt}$ and $\mathrm{V}_{\max }$ decreased simultaneously by 17 and $18 \%$. Both parameters had returned to their control value by the time of the fourth coronary angiogram. It is safe to conclude that nifedipine has a negative inotropic effect when regionally administered. The changes in $\mathrm{V}_{\max }$ and in the coronary sinus $\mathrm{O}_{2}$ saturation are shown in Fig. 5. Thirty seconds after the intracoronary administration of nifedipine, there was a marked increase of the coronary sinus $\mathrm{O}_{2}$ saturation from 36 to $63 \%$ occurring simultaneously with the drop in $\mathrm{V}_{\max }$. To what extent this increase in coronary sinus $\mathrm{O}_{2}$ saturation is due to the reduction observed in contractility or to an increase in coronary blood flow was not specifically investigated in this study. How-
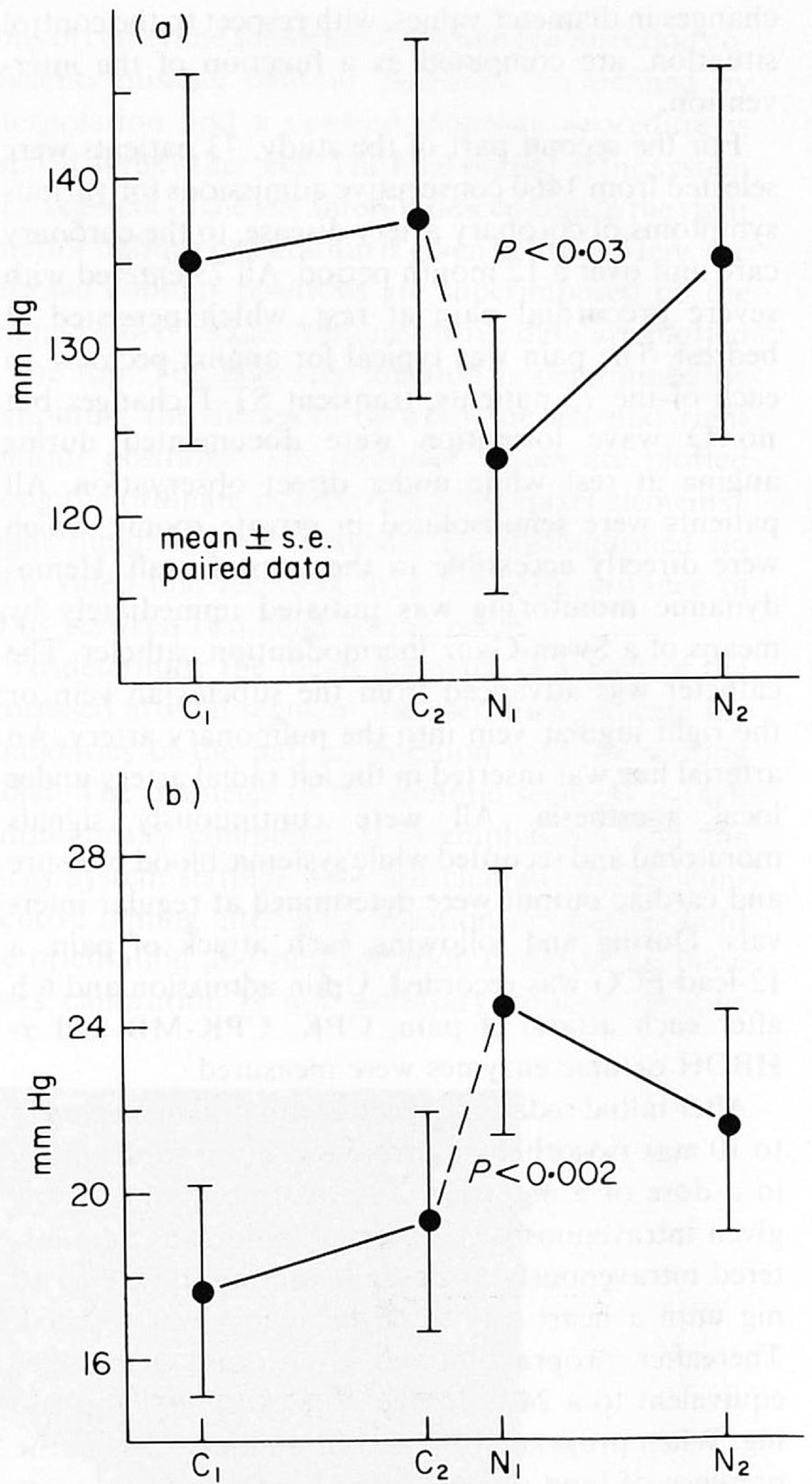

Figure 4 Peak left ventricular pressure (LVP) (a) and enddiastolic pressure (EDP) (b) during the two control $\left(C_{1}, C_{2}\right)$ and the two post-nifedipine $\left(\mathrm{N}_{1}, \mathrm{~N}_{2}\right)$ cine-angiograms.

ever, it must be emphasized that $5 \mathrm{~min}$ after the intracoronary injection of nifedipine, there was no detectable effect of nifedipine on the coronary sinus $\mathrm{O}_{2}$ saturation or on contractility.

The effects of nifedipine on the mean diameter of 11 normal and 21 poststenotic coronary segments are shown in Figs 6 and 9. In both subgroups, there was no significant difference in the mean diameter between the first and the second control cinefilm (Table 3). In other words two consecutive injections of contrast agent do not affect the vasomotility of the coronary system appreciably.

Thirty seconds after the intracoronary injection of nifedipine, there was no vasodilation of the normal 

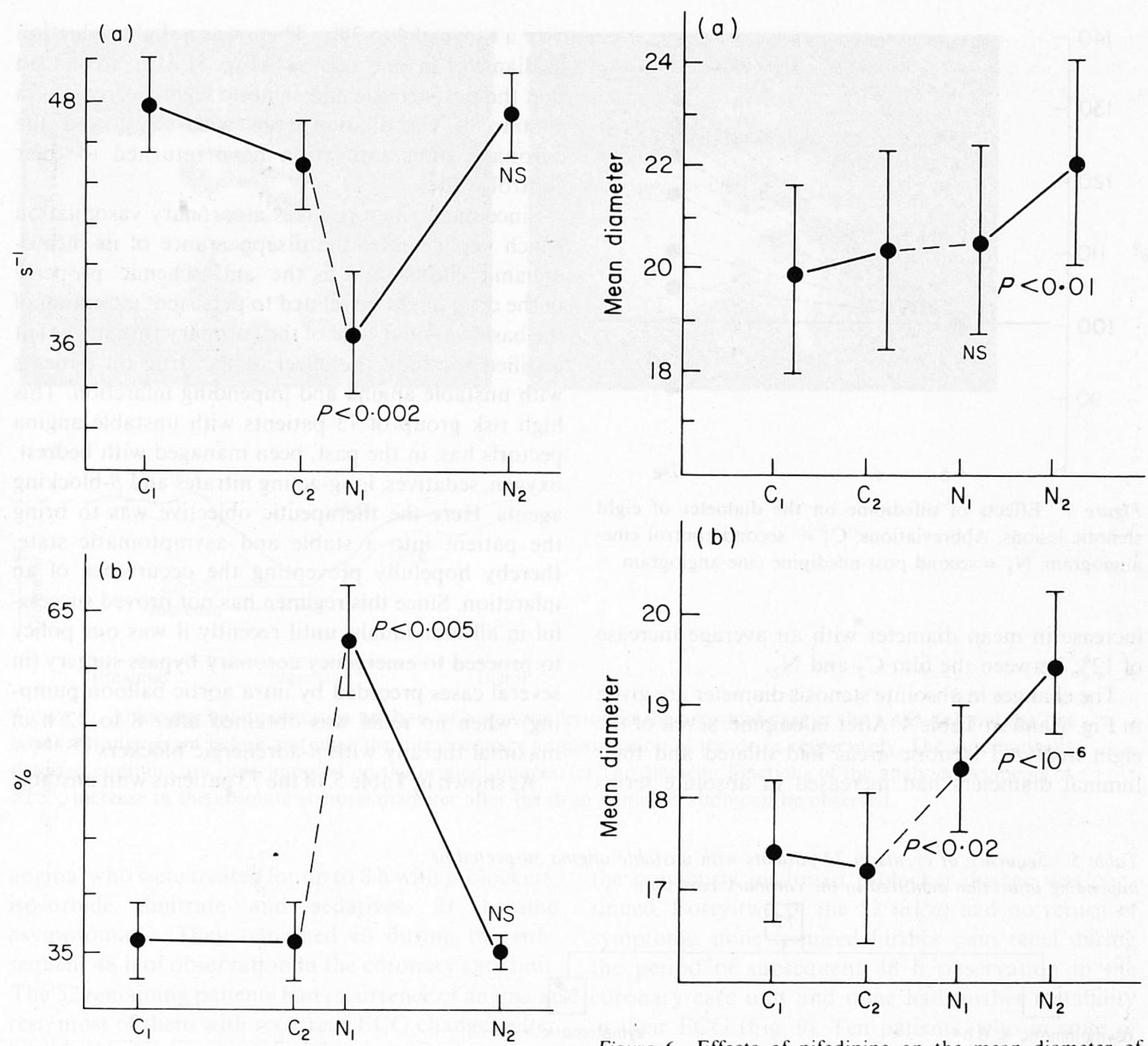

Figure 6 Effects of nifedipine on the mean diameter of (a) 11 normal and (b) 21 poststenotic coronary segments during the two control $\left(\mathrm{C}_{1}, \mathrm{C}_{2}\right)$ and the two post-nifedipine $\left(\mathrm{N}_{1}, \mathrm{~N}_{2}\right)$ cine-angiograms.

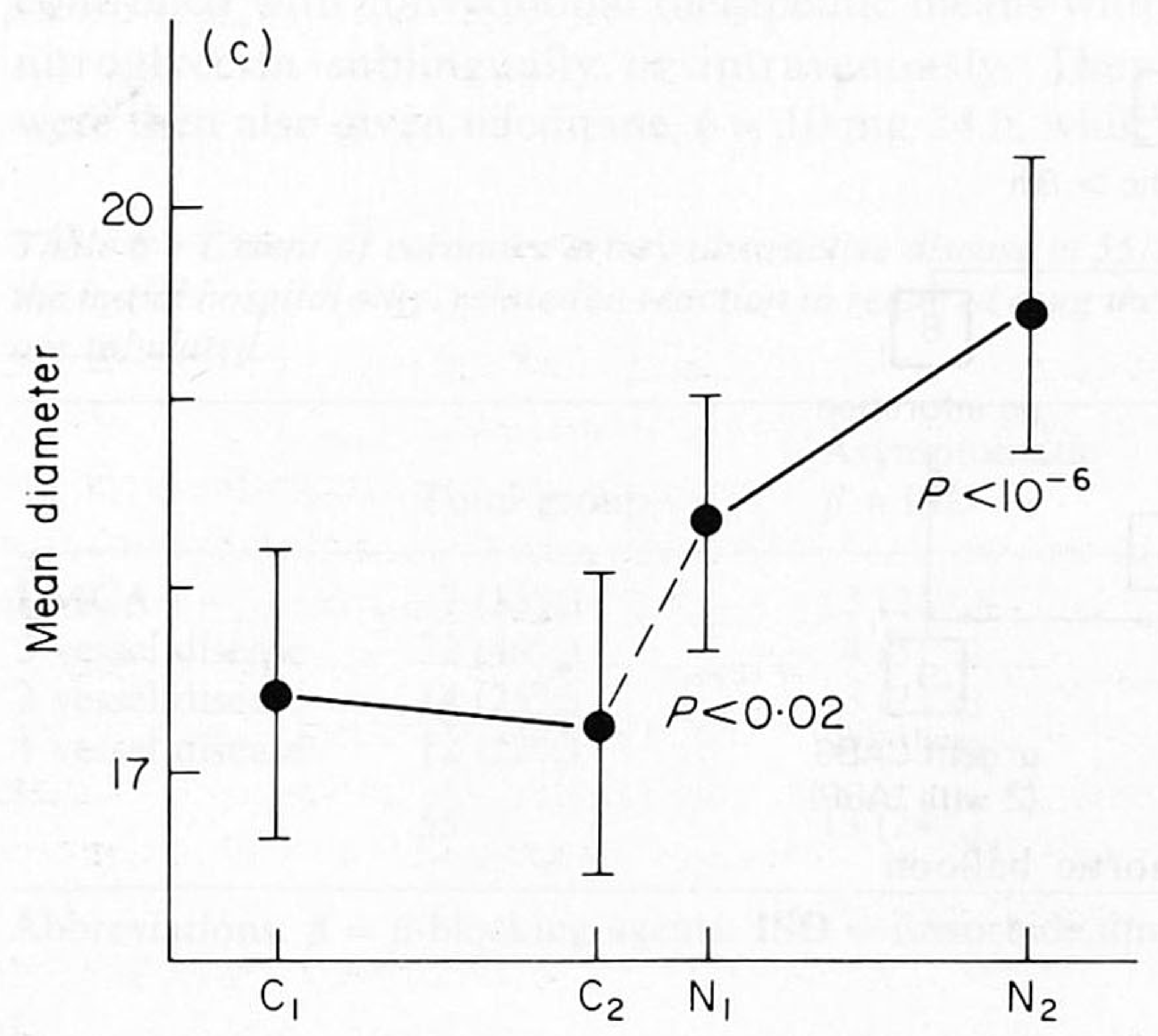

coronary segments. However, on the last film, $5 \mathrm{~min}$ later, a significant increase of $11 \%(P<0.01)$ in the mean diameter was observed.

As for the poststenotic segments, at $30 \mathrm{~s}$ after the nifedipine administration there was already a significant increase of the luminal diameter. This vasodilation persisted and even increased later on (Table 3, Fig. 6). Without exception, all segments showed an

Figure 5 (left) Changes in $\mathrm{V}_{\max }$ (a), coronary sinus saturation (b) and mean diameter of the poststenotic segment (c) during the two control $\left(\mathrm{C}_{1}, \mathrm{C}_{2}\right)$ and the two post-nifedipine $\left(\mathrm{N}_{1}, \mathrm{~N}_{2}\right)$ cine-angiograms. 


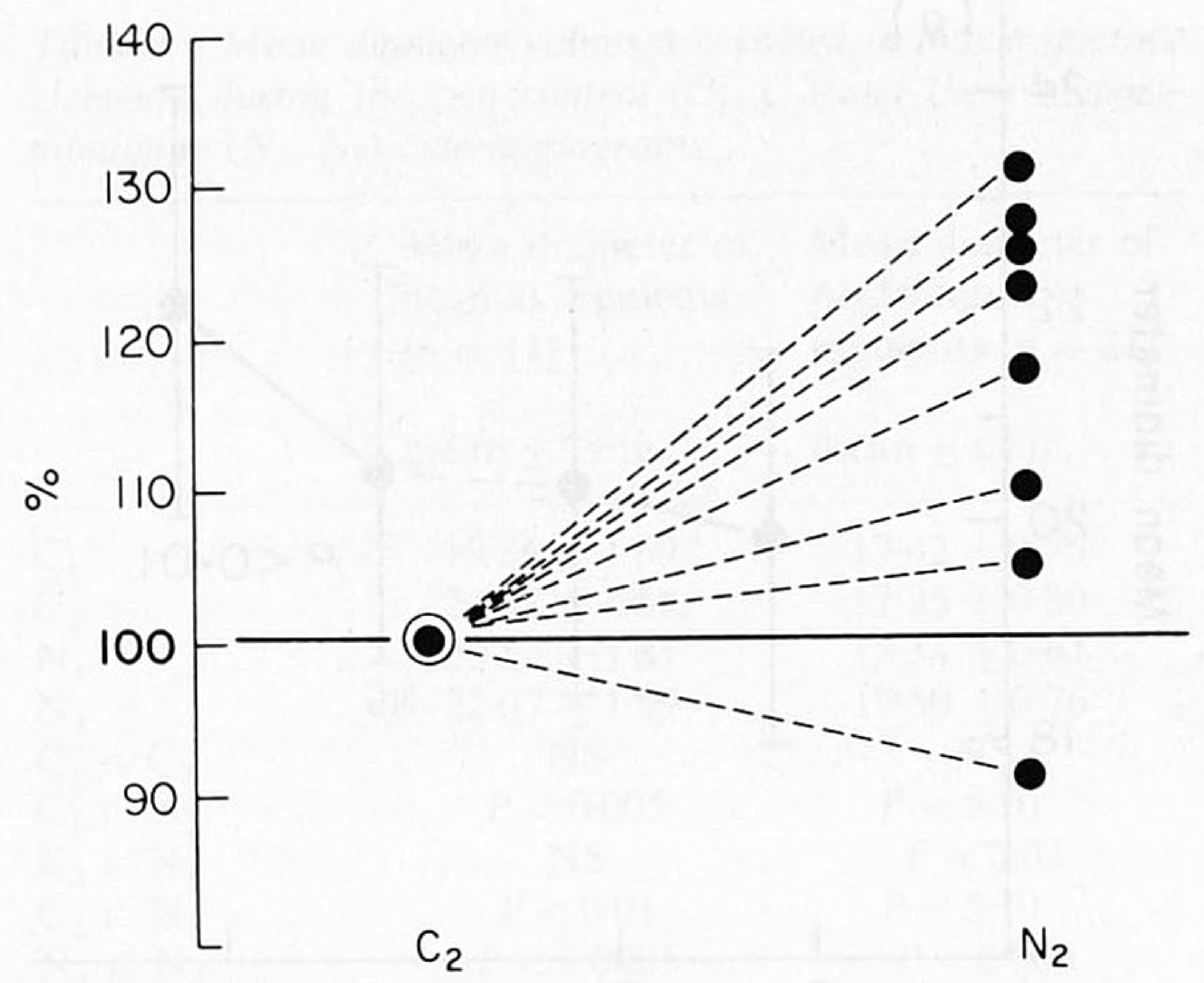

Figure 7 Effects of nifedipine on the diameter of eight stenotic lesions. Abbreviations: $\mathrm{C}_{2}=$ second control cineangiogram; $\mathrm{N}_{2}=$ second post-nifedipine cine-angiogram.

increase in mean diameter with an average increase of $12 \%$ between the film $\mathrm{C}_{2}$ and $\mathrm{N}_{2}$.

The changes in absolute stenosis diameter are given in Fig. 7 and in Table 4. After nifedipine, seven of the eight analyzed stenotic areas had dilated and their luminal diameters had increased in absolute terms over a range of 4 to $30 \%$. There was a slight reduction in diameter in one segment (Fig. 5). It is concluded that the poststenotic and stenotic segments remain in a state of vasodilation even when $\mathrm{V}_{\max }$ and the coronary sinus saturation have returned to their control values.

Since nifedipine provokes a coronary vasodilation which persists after the disappearance of its 'hemodynamic effects', and as the 'anti-ischemic' property of the drug might be related to persistent alteration of the basal vascular tone of the coronary tree, it was felt justified to study the effect of the drug on patients with unstable angina and impending infarction. This high risk group of 73 patients with unstable angina pectoris has, in the past, been managed with bedrest, oxygen, sedatives, long-acting nitrates and $\beta$-blocking agents. Here the therapeutic objective was to bring the patient into a stable and asymptomatic state, thereby hopefully preventing the occurrence of an infarction. Since this regimen has not proved successful in all individuals, until recently it was our policy to proceed to emergency coronary bypass surgery (in several cases preceded by intra aortic balloon pumping) when no relief was obtained after 8 to $12 \mathrm{~h}$ of maximal therapy with $\beta$-adrenergic blockers ${ }^{[24.25]}$.

As shown in Table 5, of the 73 patients with unstable

Table 5 Sequence of events in 73 patients with unstable angina suspected of impending infarction admitted to the coronary care unit

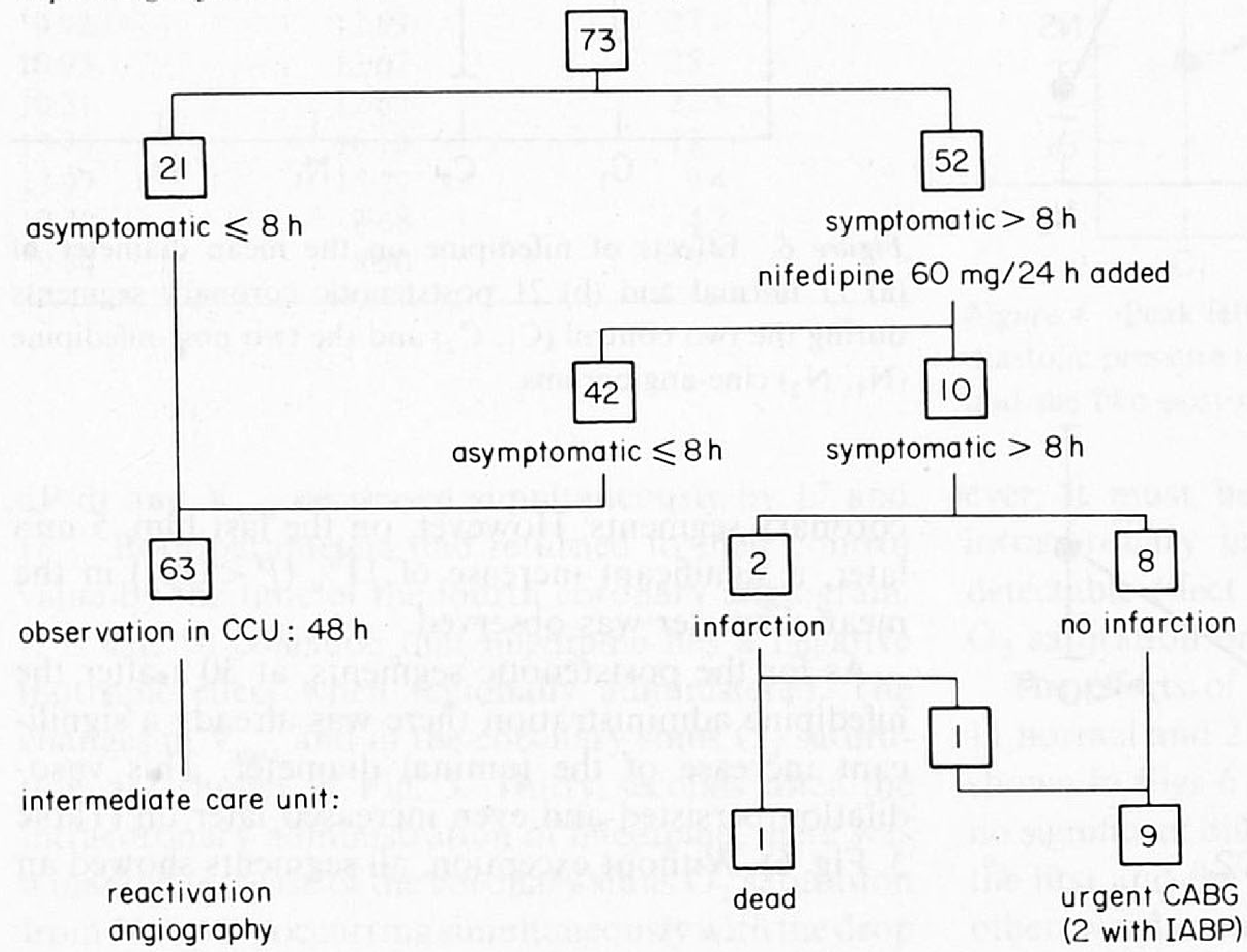

$\mathrm{CABG}=$ coronary artery bypass grafting; $\mathrm{IABP}=$ intra aortic balloon pumping. 

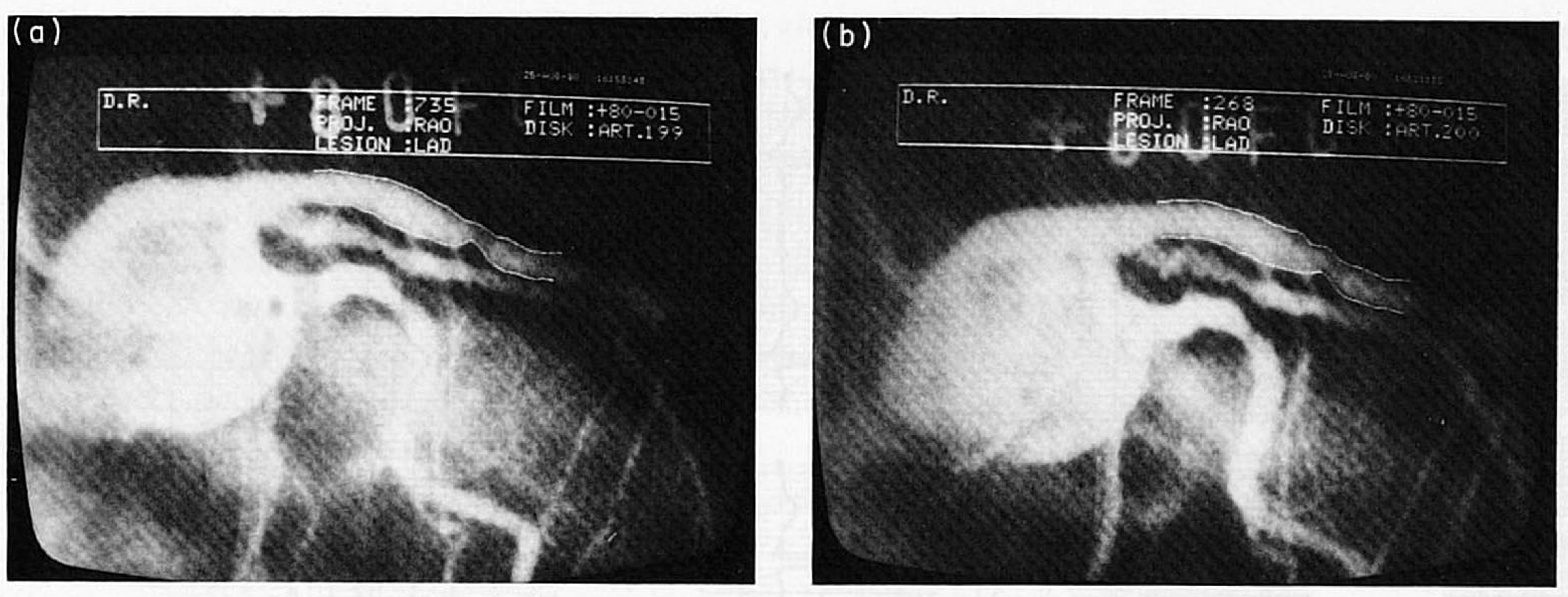

(c)

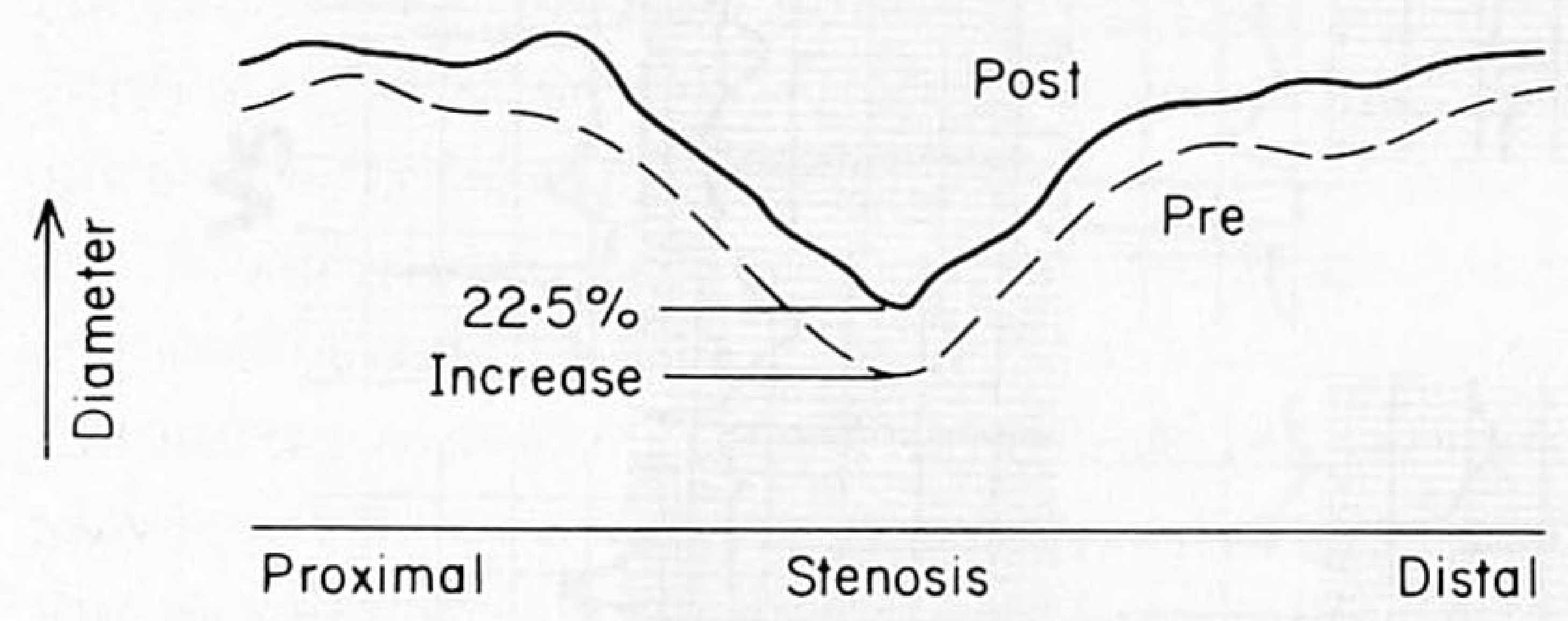

Figure 8 Angiographic quantitative analysis of a stenotic lesion in the proximal part of the LAD. (a) and (b) The coronary angiogram before and after the intracoronary administration of the drug, respectively. The automatically detected contours are superimposed on the original images. (c) The diameter functions of the analyzed segments. A $22.5 \%$ increase in the absolute stenosis diameter after the drug administration can be observed.

angina, who were treated for up to $8 \mathrm{~h}$ with $\beta$-blockers, isosorbide dinitrate and sedatives, 21 became asymptomatic. They remained so during the subsequent $48 \mathrm{~h}$ of observation in the coronary care unit. The 52 remaining patients had recurrence of angina at rest, most of them with recurrent ECG changes, after $8 \mathrm{~h}$ of such therapy. In these 52 , the angina was again controlled with conventional therapeutic means with nitroglycerin sublingually or intravenously. They were then also given nifedipine, $6 \times 10 \mathrm{mg} / 24 \mathrm{~h}$, while the previously instituted $\beta$-blocker dosage was continued. Forty-two of the $52(81 \%)$ had no return of symptoms, none required further pain relief during the period of subsequent $48 \mathrm{~h}$ observation in the coronary care unit and none had further instability in their ECG (Fig. 9). Ten patients, who in spite of the above regimen had recurrence of angina, were considered a failure to respond to nifedipine. Two of these 10 , sustained a myocardial infarction within 24 $h$ and one died. Of the other eight, two patients with

Table 6 Extent of coronary artery obstructive disease in 55/73 patients who underwent angiography during the initial hospital stay, related to reaction to required drug therapy. Only lesions with $\geqq 70 \%$ lumen reduction are tabulated

\begin{tabular}{lcccc}
\hline & Total group & $\begin{array}{l}\text { Asymptomatic } \\
\beta+\text { ISD }\end{array}$ & $\begin{array}{c}\text { Asymptomatic } \\
\beta+\text { ISD }+\mathrm{N}\end{array}$ & $\begin{array}{l}\text { Symptomatic } \\
\beta+\text { ISD + N }\end{array}$ \\
\hline LMCA & $7(13 \%)$ & $3(23 \%)$ & $2(6 \%)$ & $2(20 \%)$ \\
3 vessel disease & $22(40 \%)$ & $4(31 \%)$ & $12(38 \%)$ & $6(60 \%)$ \\
2 vessel disease & $14(25 \%)$ & $3(23 \%)$ & $10(31 \%)$ & $1(10 \%)$ \\
1 vessel disease & $12(22 \%)$ & $3(23 \%)$ & $8(25 \%)$ & $1(10 \%)$ \\
& 55 & $13(24 \%)$ & $32(58 \%)$ & $10(18 \%)$ \\
\hline
\end{tabular}

Abbreviations: $\beta=\beta$-blocking agents: $I S D=$ isosorbide dinitrate; $\mathrm{N}=$ nifedipine. 


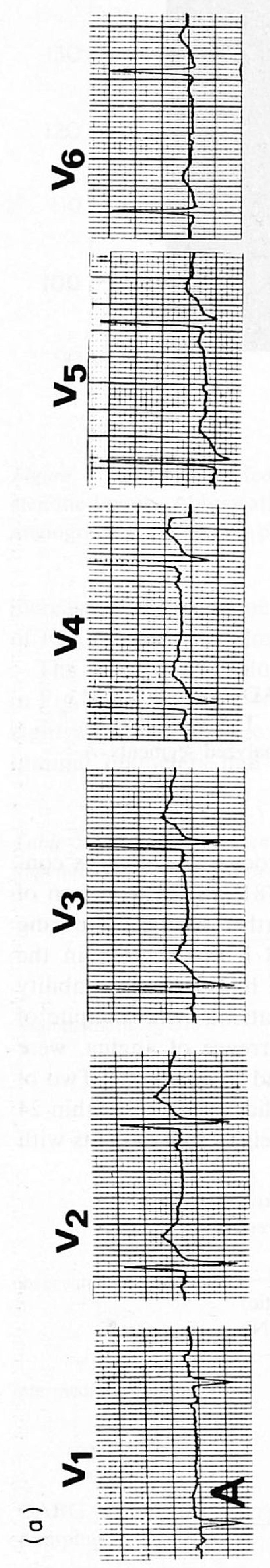

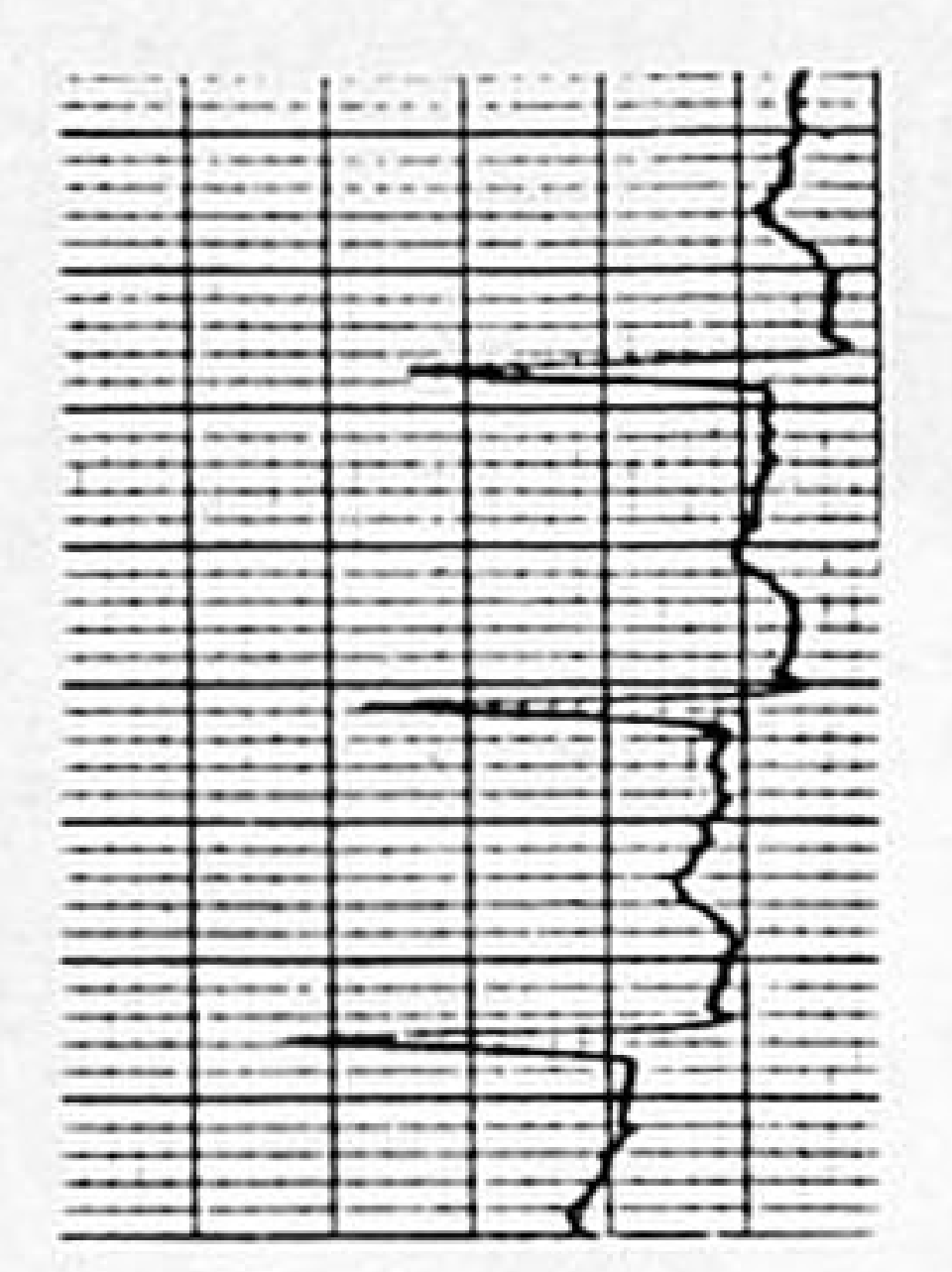
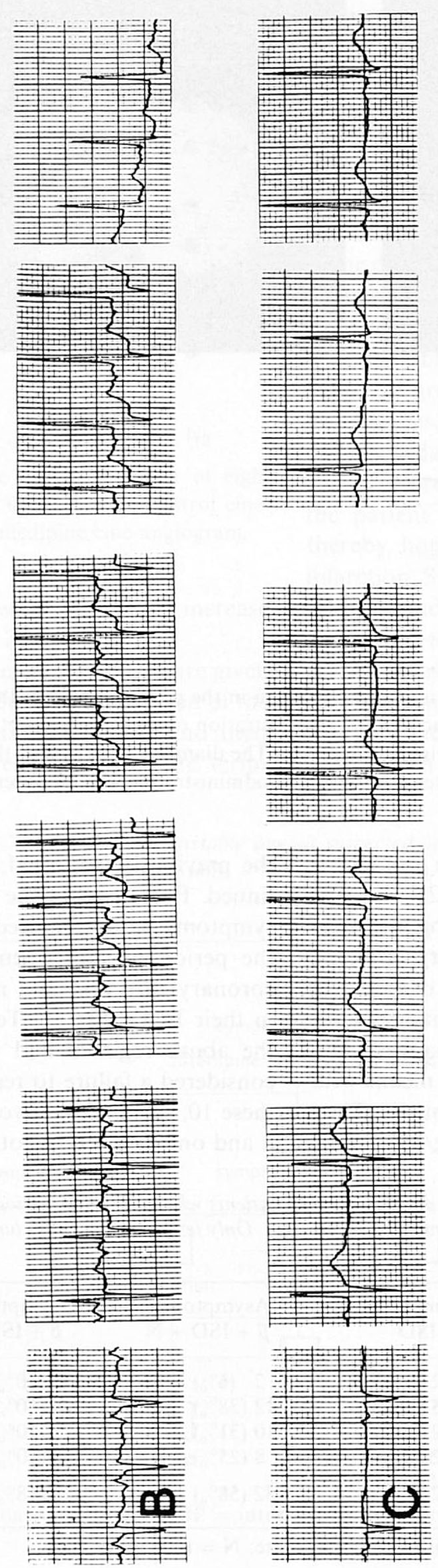
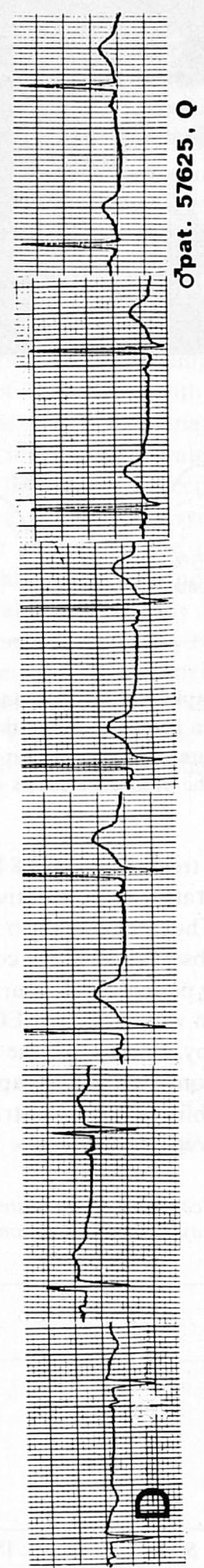

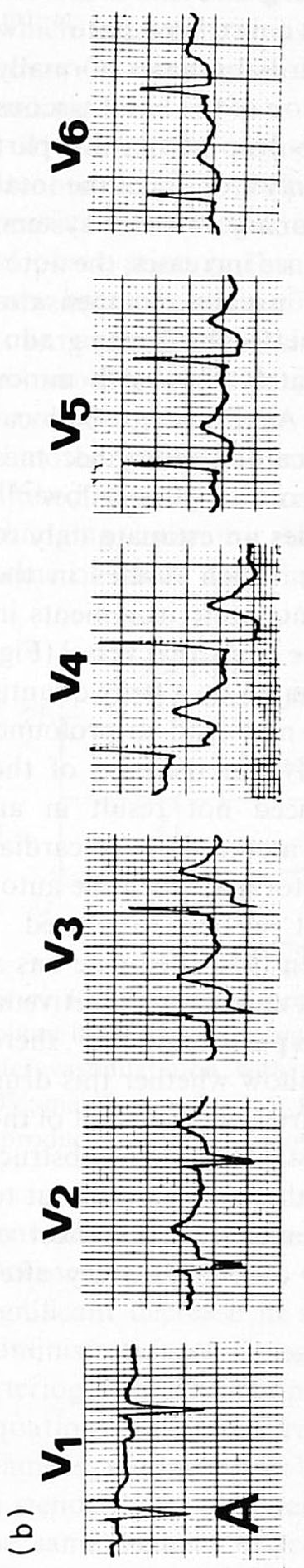
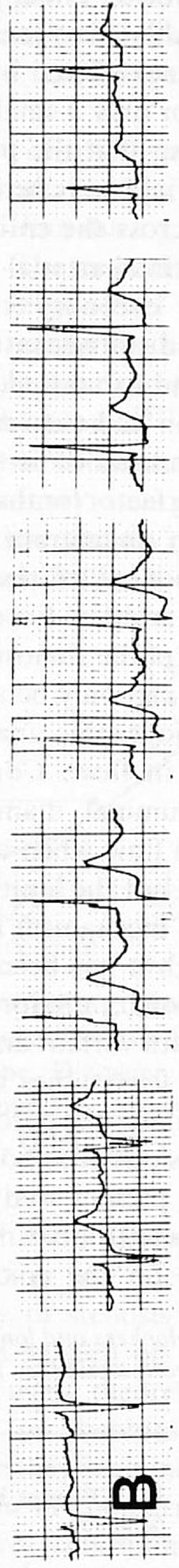
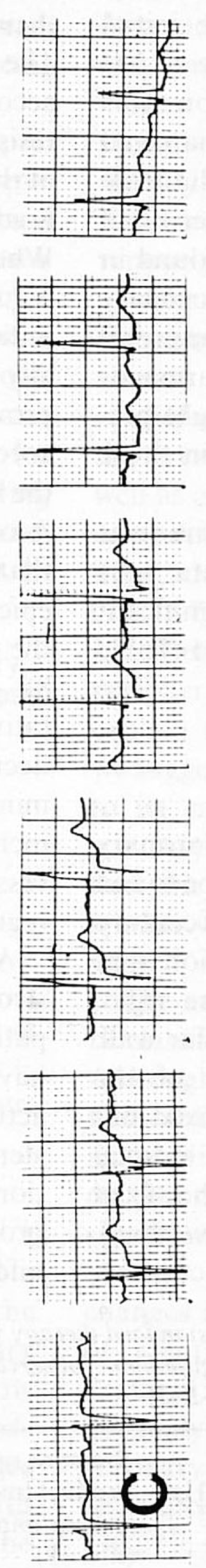

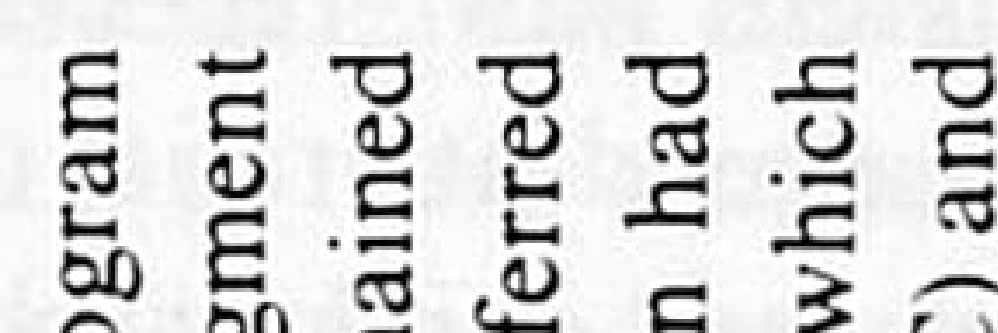

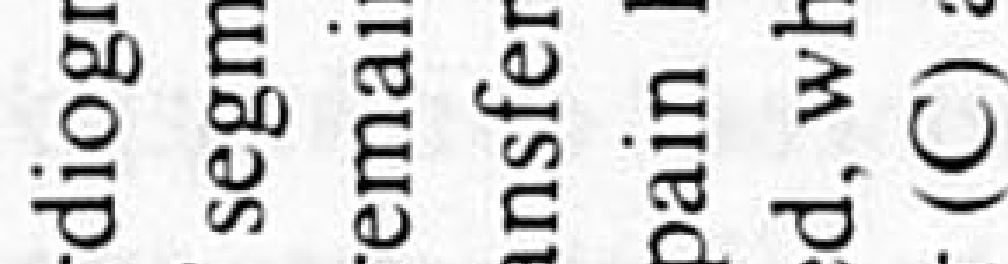

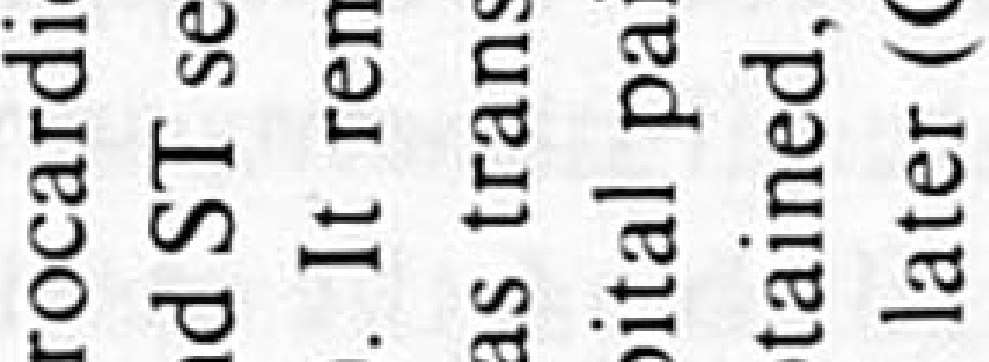

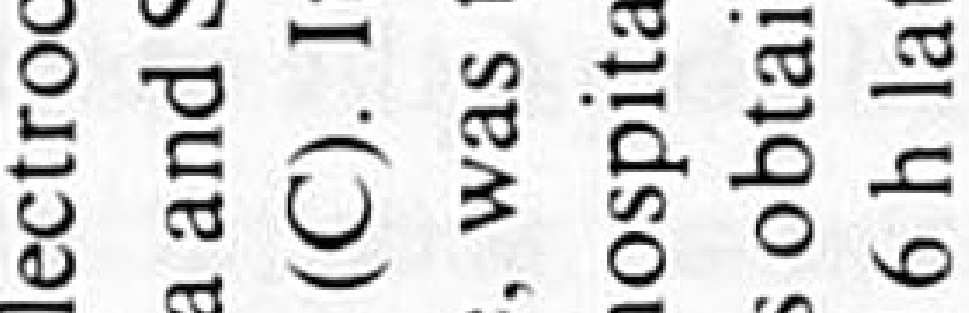
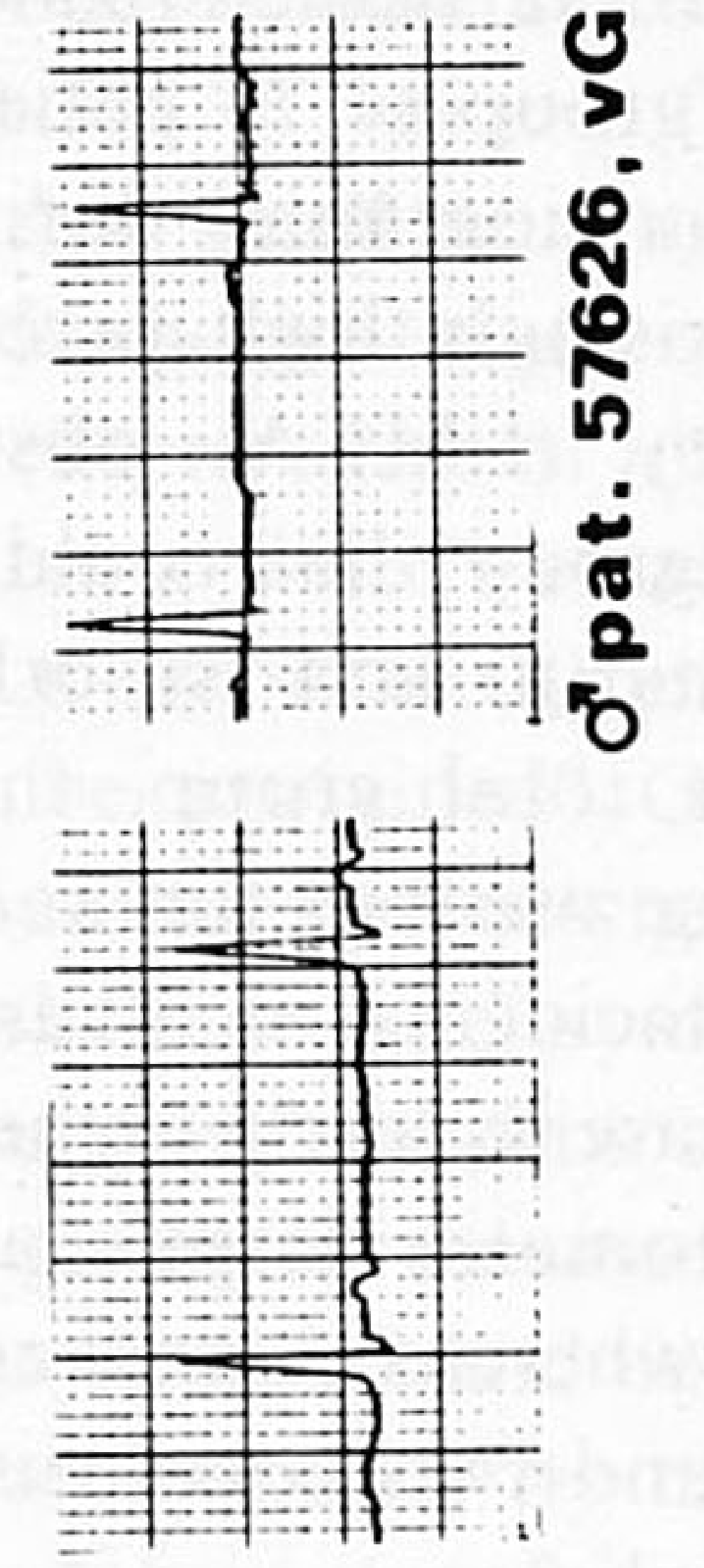

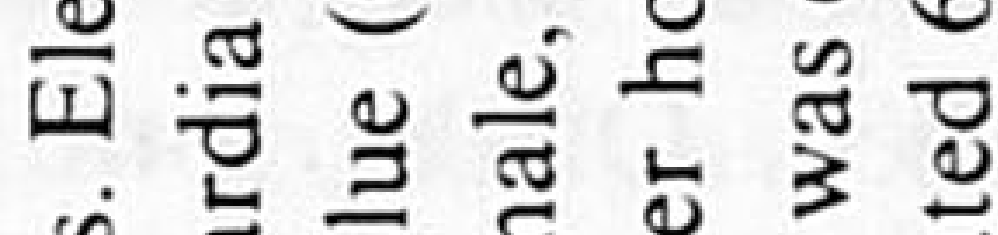

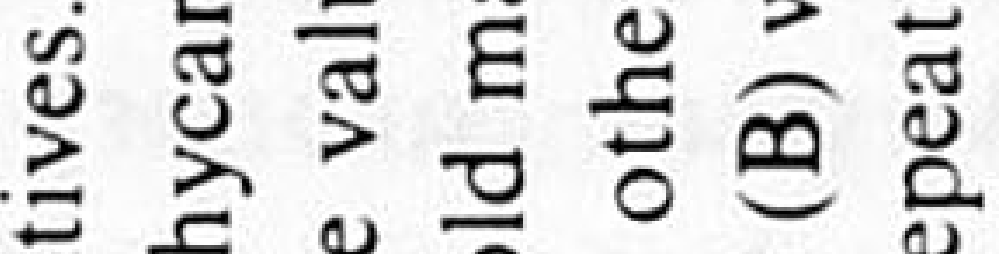

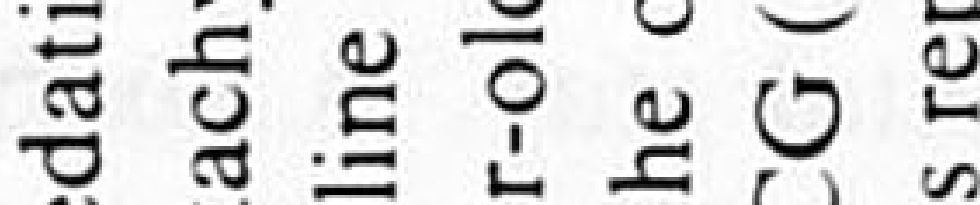

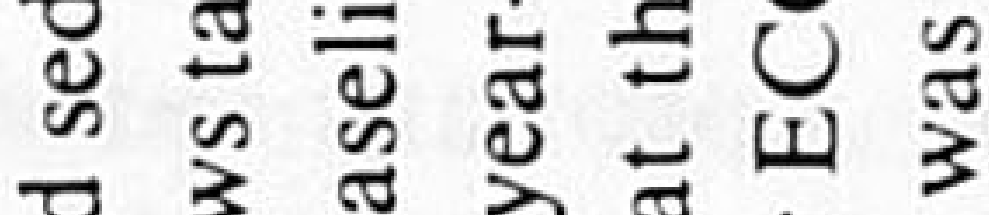

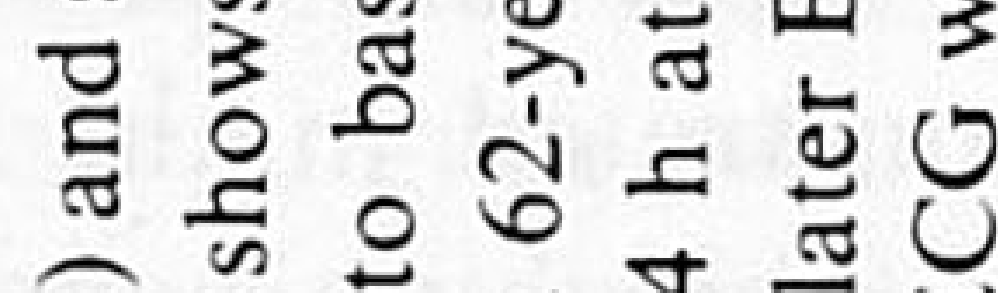
तิ б

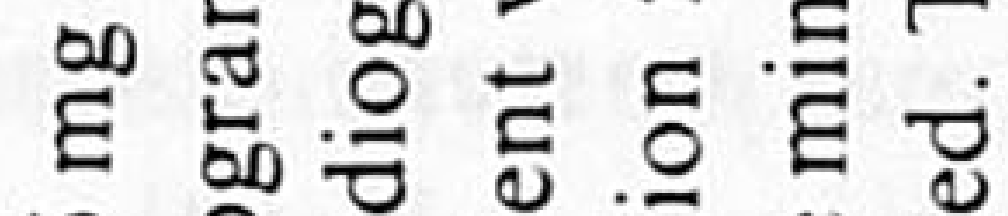

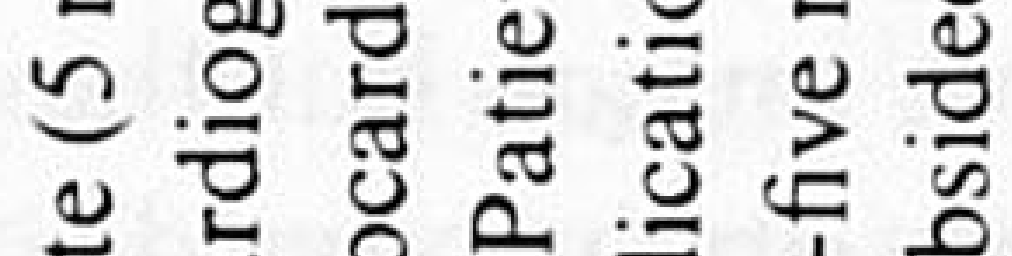

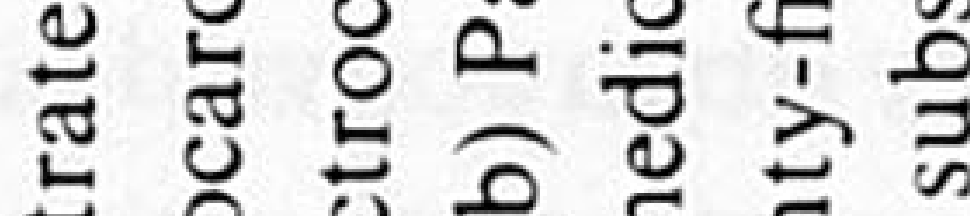
壱㣢出

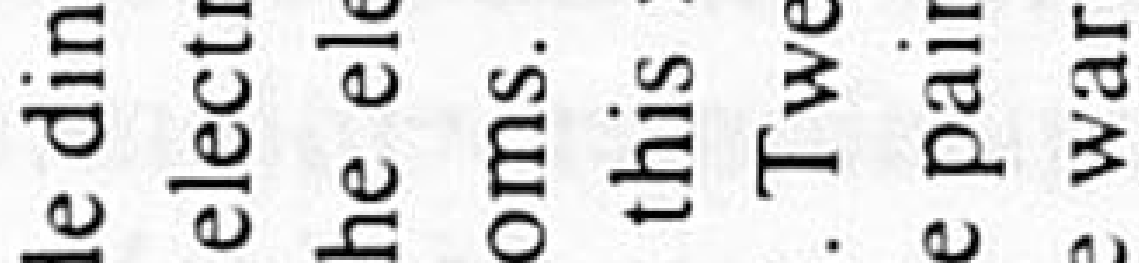
율 导

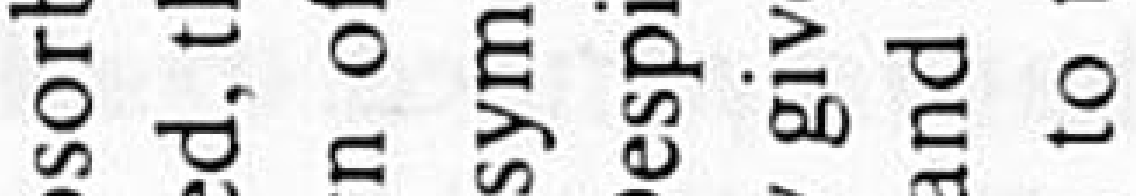
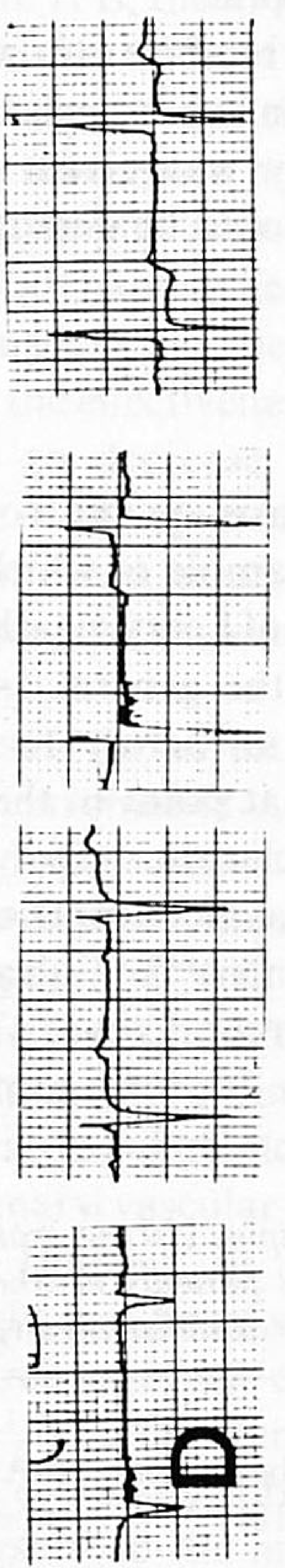
. ช б.

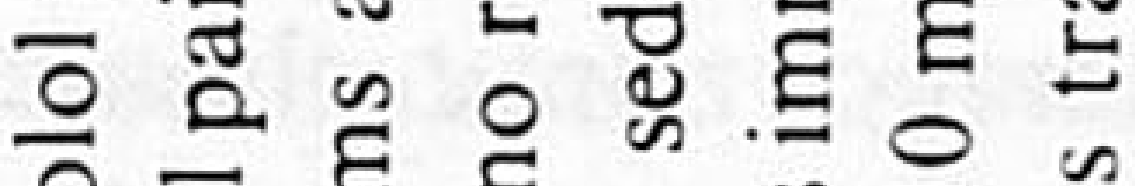

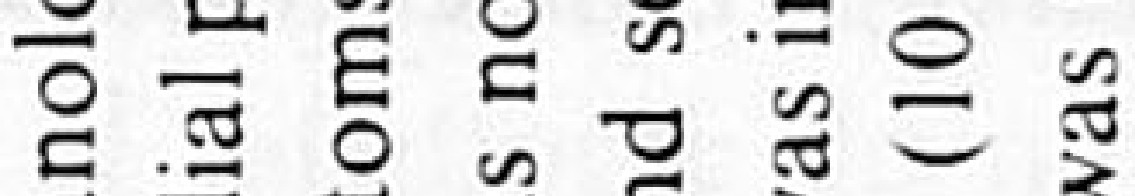
जٓ 훈

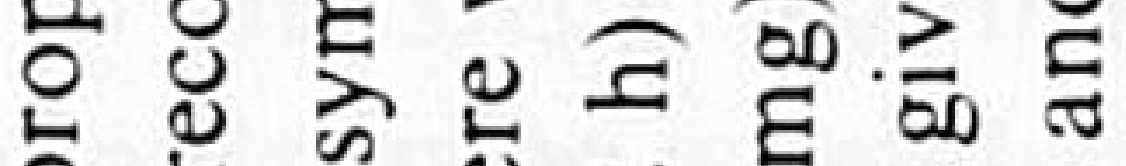

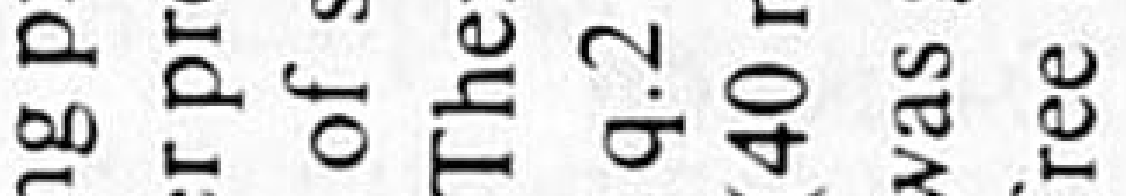
E 可 \&

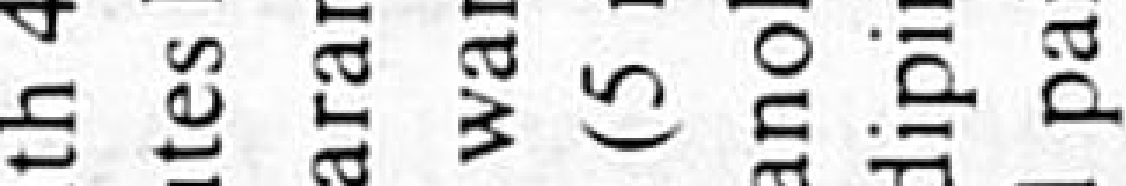

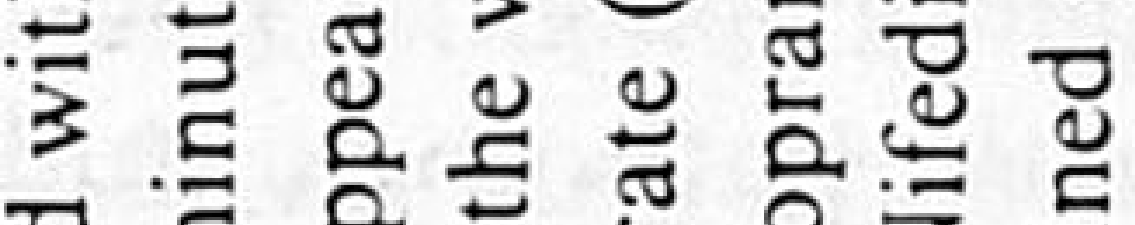

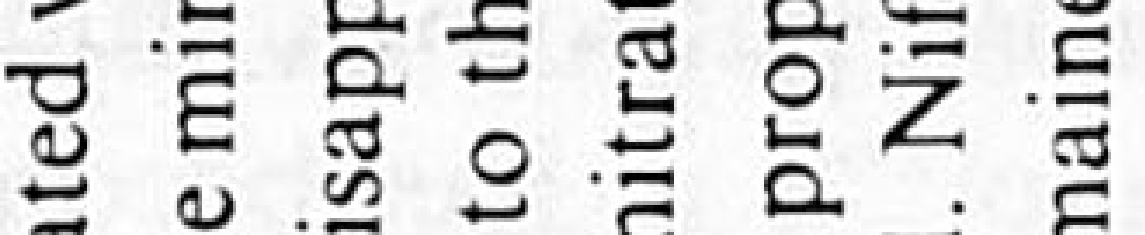

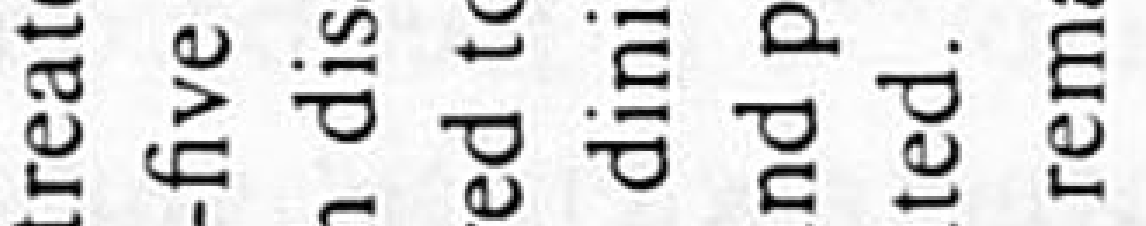

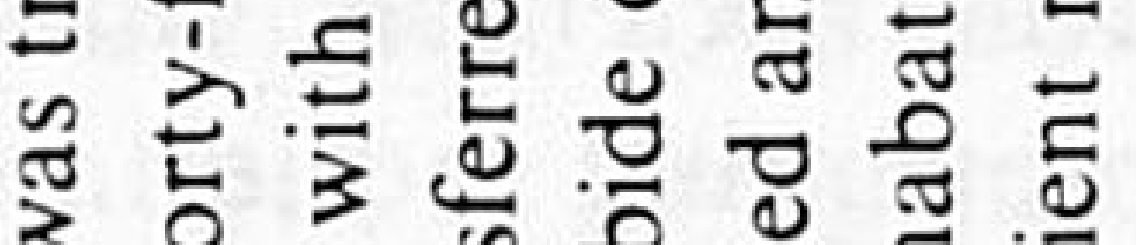

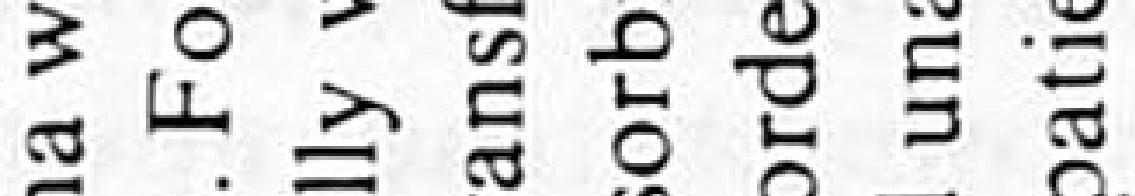

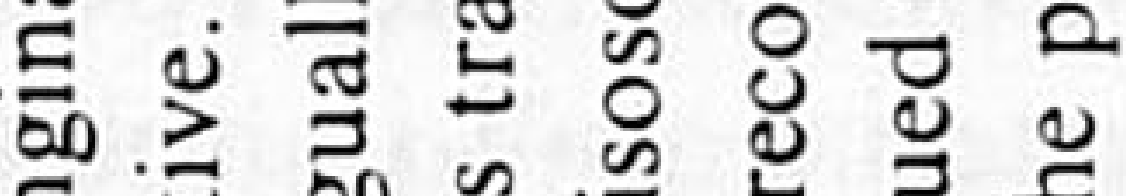
㲾 응

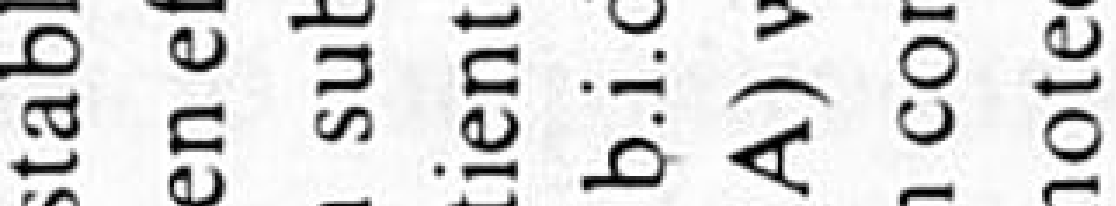
పิ

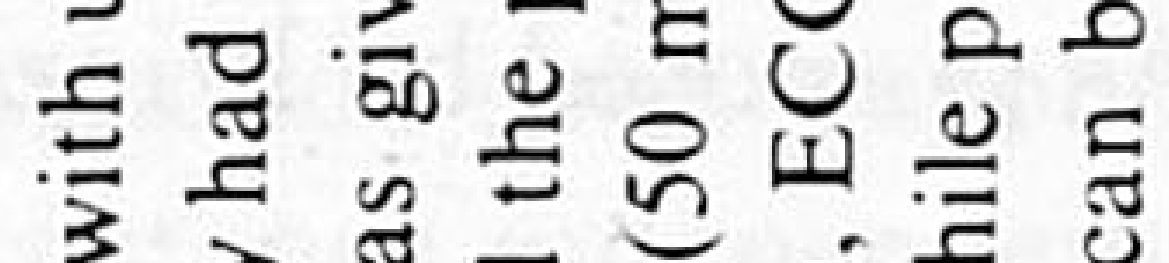

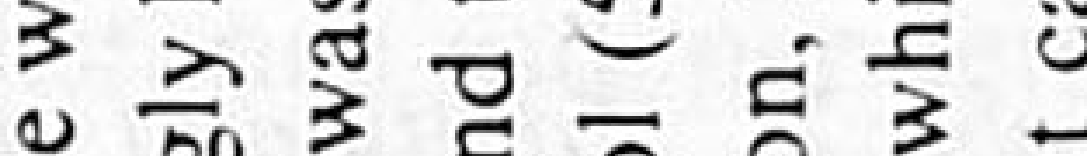
프르으응 咆高赔 엉

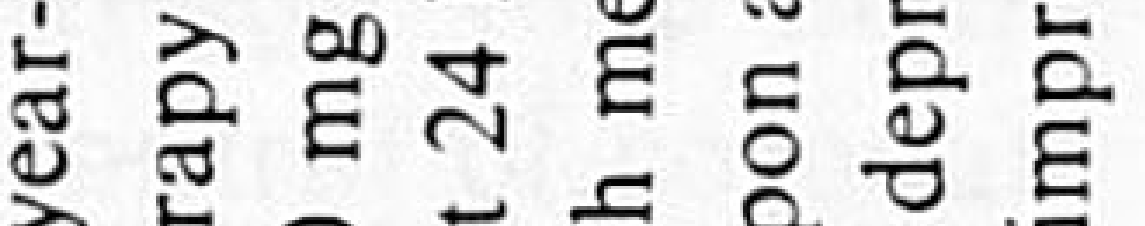

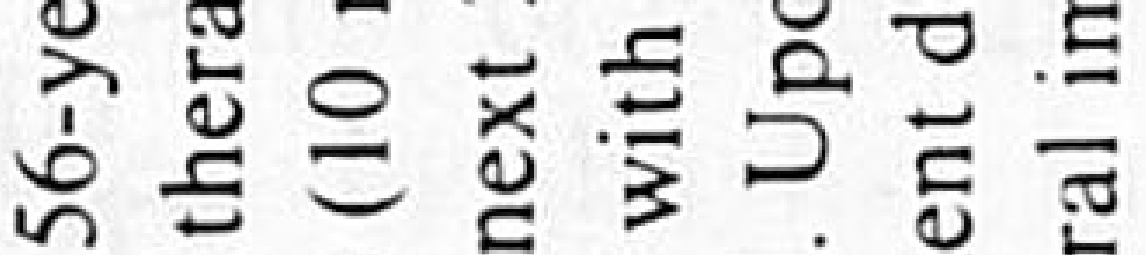

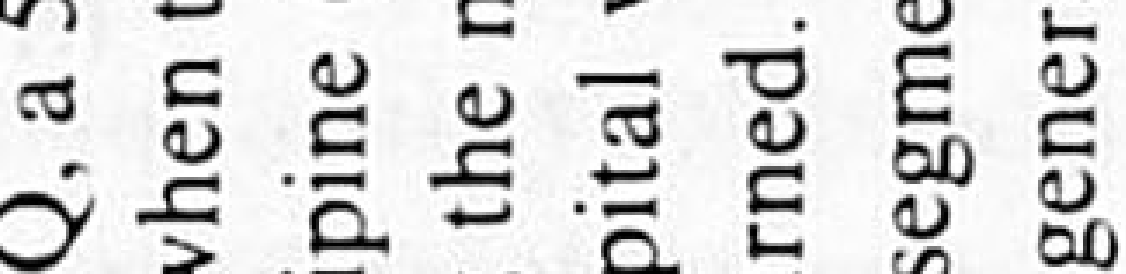

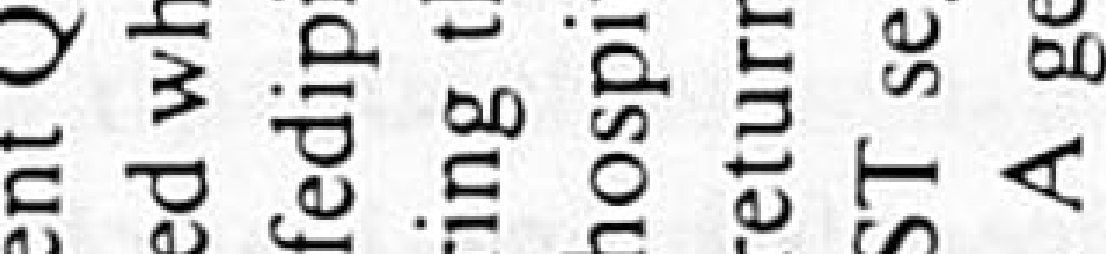

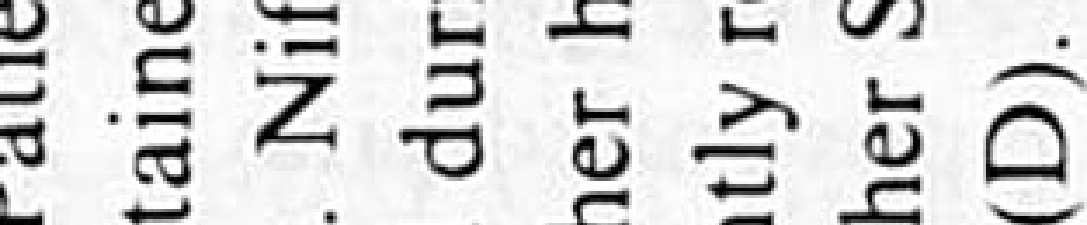

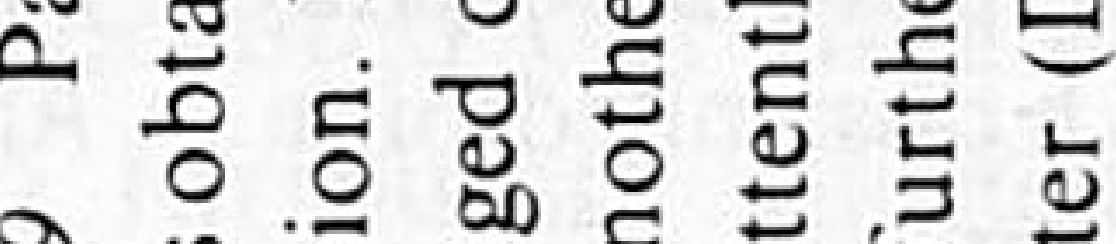

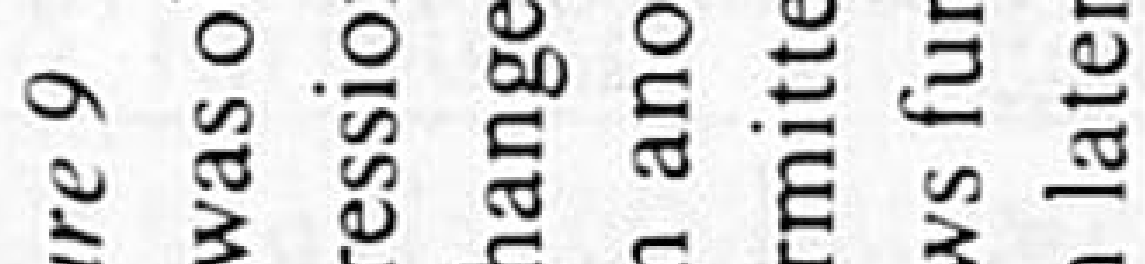

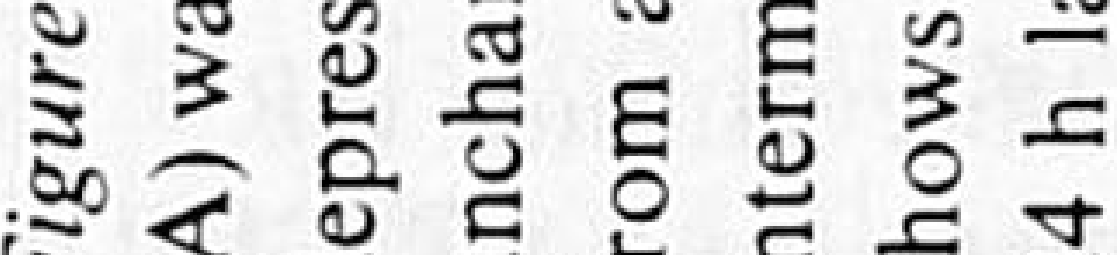


persistent pain, received intra aortic balloon pumping with immediate relief of their symptoms. Nine patients underwent coronary bypass grafting and all are alive as are all patients who were placed on nifedipine.

In Table 6 the extent of coronary artery obstructive disease as seen at cardiac catheterization has been detailed. Of the total group of 73 patients, $55(75 \%)$ underwent coronary angiography during the initial hospital stay. A surprisingly high percentage of left main coronary artery (LMCA) obstruction was demonstrated in the group that could be managed with $\beta$-blocking agents $(\beta)$ and isosorbide dinitrate (ISD) alone. For the total group, the severity of coronary artery disease was not unlike that found in stable angina but the incidence of advanced coronary artery obstructive disease is clearly higher in the group that remained symptomatic despite all pharmacological interventions, whereas there was a slight predominance of single and two vessel disease in those that responded to nifedipine.

The hemodynamic response to nifedipine was studied in 18 patients in whom baseline data were available before therapy was given. No significant hemodynamic changes could be demonstrated (Table 7).

\section{Discussion}

Despite earlier emphasis on the role of coronary artery spasm, a good example of which can be found in the pathologic studies of Leary, nearly a half century $\mathrm{ago}^{[26]}$, it has become the general assumption that atherosclerosis causes an artery to become rigid, preventing motion at that point in the vascular wall. However, the atherosclerotic involvement of the arterial wall is not always concentric and fixed but may be frequently eccentric ${ }^{[26.27]}$, leaving a normal wall over part of its circumference. Thus the "fixed stenosis' concept may be due for a complete overhaul. As proposed by Prinzmetal in his original description, it seems now eminently reasonable to assume that the clinical manifestations of variant angina might be due to normal or excessive arterial coronary vasomotion superimposed on an organically narrowed vessel ${ }^{[1]}$. Several reports in the recent literature suggest that major coronary arteries can approximately halve their luminal diameter under physiological conditions from their most dilated to their most constricted state ${ }^{[4-10]}$ The resistance offered by epicardial arteries normally accounts for only a small portion of the basal viscous resistance so that the pressure drop across this part of the arterial bed is perhaps only 1 or $2 \%$ of the total gradient across the entire coronary vascular system. When proximal arterial resistance increases, the autoregulatory coronary reserve usually compensates initially by distal relaxation. This feedback may gradually become exhausted, ultimately even with minor provocation and even at rest. At this point the local coronary resistance in the epicardial artery becomes the limiting factor for the total coronary blood flow ${ }^{[28]}$. A coronary angiogram provides an estimate only of that component of resistance which resides in the epicardial arteries. Even so, moderate increments in the degree of the stenosis of the epicardial vessel (Fig. 8) - which can only be appreciated by a truly quantitative angiographic analysis - may lead to profound decreases in flow. Conversely, an increase of the minimal luminal diameter need not result in an increase in flow when at that moment the epicardial vessels are not the limiting factor and when the autoregulatory mechanism has not yet been exhausted.

Although it has been proven that nifedipine has a strong coronary dilatory effect and is very effective in patients with variant angina in particular ${ }^{[1-13]}$, there have been few studies which show whether this drug actually dilates the coronary artery at the point of the stenotic lesions or at points distal to the fixed obstructions. The present study was therefore carried out to provide quantitative measurements of the effect of nifedipine on the epicardial coronary artery after

Table 7 Addition of nifedipine (10 mg oral) when standard therapy with $\beta$-blockers and longacting nitrates failed in 18 patients in whom pre-nifedipine observations were available; no significant change could be demonstrated (paired t-test)

\begin{tabular}{lllll}
\hline & $\begin{array}{l}\text { HR (beat/min.) } \\
(\mathrm{n}=18)\end{array}$ & $\begin{array}{l}\overline{\mathrm{mAP}}(\mathrm{mm} \mathrm{Hg}) \\
(\mathrm{n}=18)\end{array}$ & $\begin{array}{l}\text { Pressure rate } \\
\text { product }(\mathrm{mm} H g \\
\times \text { beat/min }) \\
(\mathrm{n}=18)\end{array}$ & $\begin{array}{l}\text { PCWP }(\mathrm{mm} \mathrm{Hg}) \\
(\mathrm{n}=18)\end{array}$ \\
\hline $\begin{array}{l}\text { Pre-nifedipine } \\
\text { 1 h post-nifedipine }\end{array}$ & $70 \pm 9 \pm 9$ & $97 \pm 17$ & $6445 \pm 1562$ & $7 \pm 3$ \\
4h post-nifedipine & $70 \pm 16$ & $95 \pm 13$ & $6854 \pm 1372$ & $8 \pm 3$ \\
\hline
\end{tabular}

Abbreviations: $\mathrm{HR}=$ heart rate in beats $/ \min ($ mean $\pm \mathrm{s} . \mathrm{d}.) ; \overline{\mathrm{m}} \mathrm{AP}=$ mean arterial pressure $($ mean \pm s.d.); $\overline{P C W P}=$ pulmonary capillary wedge pressure $($ mean \pm s.d. $)$. 
direct intracoronary administration. This route of administration was employed in order to dissociate its coronary vasodilatory effect from its direct myocardial action and its peripheral afterload reduction effect $^{[20,29-31]}$. The data from hemodynamic studies indicate that when nifedipine is regionally administered, it has a transient negative inotropic effect, which induces a transient increase of the coronary sinus $\mathrm{O}_{2}$ saturation because less oxygen is being utilized.

However, the vasodilation of all three, the prestenotic, stenotic and poststenotic, coronary segments persists much longer, at least than during the period of observation in this study. The essential question now becomes: what effect do large vessel vasomotor tone and distal arteriolar resistance have on a proximal lesion? The conflicting data and hypotheses have been recently reviewed by Gould ${ }^{[32]}$. He states that there exist different possible mechanisms for altered severity of 'fixed' coronary stenoses during changing vasomotor states of the coronary circulation, some of which are schematized in Figs 8 and 10. In

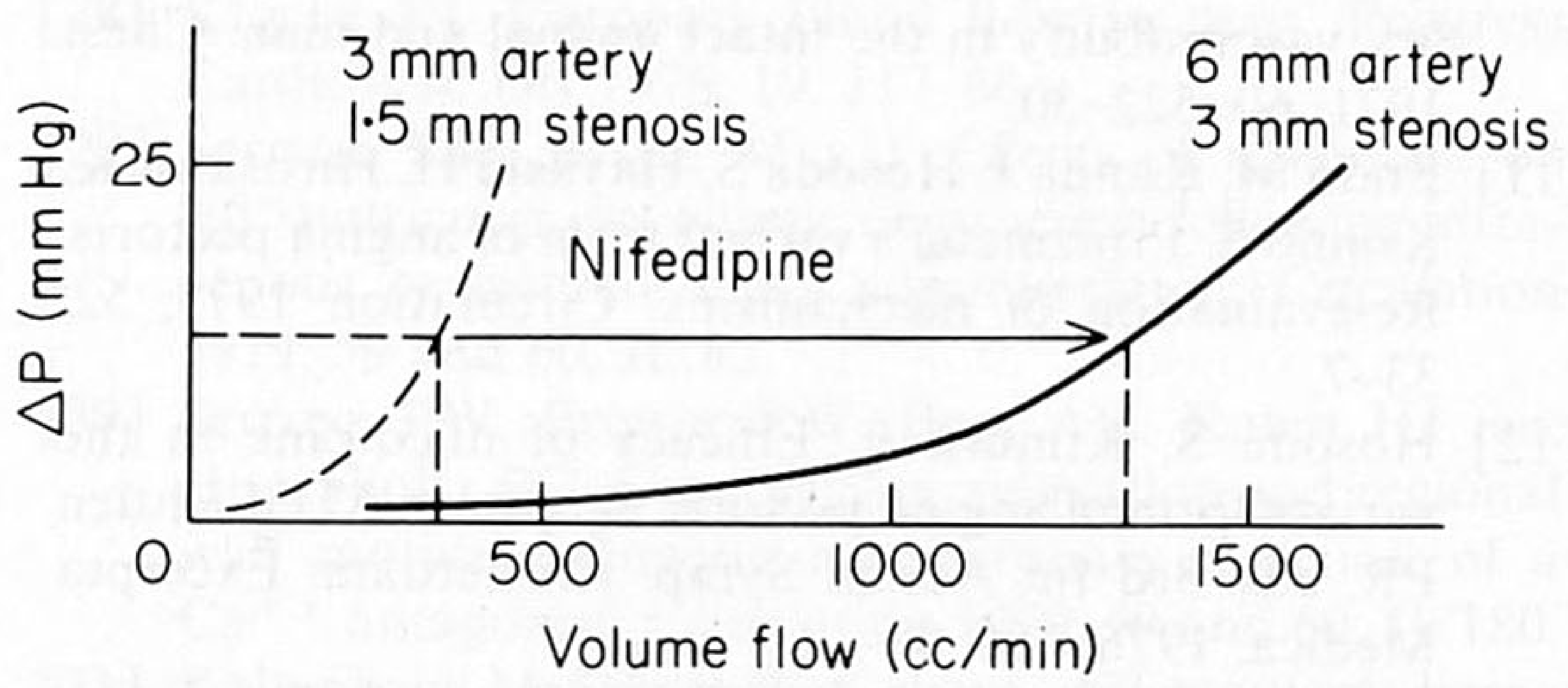

Figure 10 Relation of pressure gradient $(\triangle \mathrm{P})$ and arterial volume flow for physiologically equal stenoses before and after vasodilatation with nifedipine. Diameter stenosis = $50 \%$; maxiflow $=4 \times \uparrow ; \triangle P=25 \mathrm{~mm} \mathrm{Hg}$. (Modified figure, reproduced with permission of KL Gould.)

contrast to these experimental data, Brown et al. ${ }^{[7]}$, Doerner et al. ${ }^{[33]}$ and Oravetz et al. ${ }^{[5]}$ described a significant decrease in severity of stenosis after the administration of nitroglycerin as seen on coronary arteriograms. Their approach, using theoretical flow equations and measurements of absolute stenosis diameter, is appropriate because they examine changes in stenosis after an intervention in comparison with the same stenosis under control conditions. In the current study, absolute stenosis diameter was also obtained in order to compare the geometric severity of the same area in the same artery before and after the administration of nifedipine. The theoretical relationship between the pressure gradient and arterial volume flow for physiologically equally severe stenoses in a vasoconstricted and a vasodilated artery is shown in Fig. 10. The physiologic severity in this example is defined as the capacity to increase flow four times over resting value with a maximal pressure gradient of $25 \mathrm{~mm} \mathrm{Hg}$. Thus, stenoses of equal physiological severity in arteries of different sizes appear unequal if analyzed in terms of volume flow equations. These data indicate that small decreases in vasomotor tone may have profound hydraulic effects.

How is the effectiveness of nifedipine in the second group of patients with unstable angina who had already been $8 \mathrm{~h}$ on treatment with nitrates and $\beta$-blockers to be explained? Given orally or intravenously in man, nifedipine significantly reduces the peripheral resistance and systemic pressure ${ }^{[34,35]}$. However, in our patients, $\beta$-blockers and nitrates had already been given to maximally reduce the myocardial oxygen demand and its major determinant, the pressure rate product by reducing heart rate as well as afterload. It is, therefore, not too surprising to see that the administration of nifedipine did not result, in an additional decrease of the pressure rate product (Table 7), when these were measured 1 and $4 \mathrm{~h}$ later. In other words, in the patients studied, the known peripheral hemodynamic effects of nifedipine do not explain the symptomatic effects of the drug. Rather we suggest that the effectiveness of nifedipine is related to its capacity to decrease the calcium-dependent contractile tone of the epicardial coronary arteries so that they became less sensitive to vasoconstricting stimuli which may have resulted from the ischemic state $^{[15-17]}$.

The mechanisms for adjusting arteriolar tone may be classified as neurohumoral, metabolic or myogenic. Although most basic scientists have regarded neurohumoral mechanism as much less important than metabolic, the potential role of this type of control on coronary vascular smooth muscle has undergone significant re-examination during the last decade ${ }^{[36]}$. Several authors have demonstrated spontaneous changes in coronary vascular resistance independent of identifiable changes in myocardial metabolic demand $d^{[37-40]}$. It has been suggested that there is normally a degree of basal constrictor tone in the coronary bed ${ }^{[41]}$. The myogenic control of coronary resistance was originally proposed by Bayliss in $1902^{[42]}$, who described the intrinsic ability of blood vessels to respond to changes in transmural pressure. This mechanism is not generally considered to have a dominant role, but it must be pointed out that it has been difficult up to now to formulate studies capable of defining the importance of this mechanism in atherosclerotic blood vessels ${ }^{[43]}$. Berne and co- 
workers have tested different vaso-active agents such as adenosine, nitroglycerin and calcium antagonists for their ability to affect the induced action potential of isolated large $(\geqq 1.0 \mathrm{~mm})$ and small $(\leqq 500 \mu \mathrm{m})$ coronary arteries ${ }^{[44]}$. Adenosine blocked the calciumdependent action potential in small coronary arteries, but had no effect on the action potential in large arteries. In contrast, nitroglycerin blocked the action potential in large coronary arteries, but not in small ones. Calcium antagonists blocked the action potential irrespective of the size of the vessel. Nifedipine is able to block completely the autoregulation of the renal vascular bed whereas glyceryl trinitrate fails to impair this autoregulation ${ }^{[45]}$. Since autoregulation of blood flow is defined as the intrinsic regulatory mechanism of a vascular bed to maintain its blood flow at a constant rate regardless of changes in perfusion pressure, these experimental data emphasize the advantages of nifedipine over nitrates in affecting the coronary vascular system. In keeping with these observations is the persistent relief of pain in patients with unstable angina pectoris reported in this study who were still symptomatic while on $\beta$-blocker therapy. This is probably due to a specific action of nifedipine on the arteriolar tone of the major epicardial and the smaller coronary arteries which persisted over a $48 \mathrm{~h}$ period and stabilized what had been a very brittle condition. The fact that in 42 of the 52 such relief, although admittedly induced by yet another dose of nitroglycerin, persisted for the entire period of observation is a strong argument in favor of this mechanism. The hypothesis has also been put forward that the subset of patients with inappropriate vasoconstriction and suspected coronary artery spasm may worsen with $\beta$-adrenergic blockade ${ }^{[46]}$. In fact, Yasue has specifically argued against $\beta$-blockers in this group of patients because of the $\beta_{1}$-blocking, and thus potentially vasoconstrictive action. Since in this series of patients, unresponsive to $\beta$-blockade, the response to nifedipine was so consistent (and just as effective as had been pain relief from $\operatorname{IABP}^{[25]}$ ), there is little doubt that nifedipine in this group of patients, was the sole agent which kept the balance in their favor. Does nifedipine in these patients actually relieve excessive vasoconstriction? Only further studies, with direct measurement of coronary blood flow and measurement of coronary anatomy during the attack will answer this question with definity.

\section{References}

[1] Prinzmetal M, Kennamer R, Merliss T, Wada T, Bor N. Angina pectoris, I. A variant form of angina pectoris. Am J Med 1959; 27: 375-88.
[2] Pickering GW. Vascular spasm. Lancet 1951; 2: 845-50.

[3] MacAlpin RN. Contribution of dynamic vascular wall thickening to luminal narrowing during coronary arterial constriction. Circulation 1980; 60, 2: 296-301.

[4] Feldman RL, Pepine CJ, Curry RC, Conti CR. Coronary artery responses to graded doses of nitroglycerin. Circulation 1978; 58: II-25.

[5] Oravetz R, Lee G, Baker L, Titus P, Joye JA, Kaku R, Bogren H, Mason DT. Prominent dilation of stenotic coronary artery lesions following sublingual nitroglycerin by quantitative arteriography. Circulation 1978; 58: II-25.

[6] Hood WP Jr, Amende I, Simon R, Lichtlen PR. The effects of intracoronary nitroglycerin on left ventricular systolic and diastolic function in man. Circulation 1980; 61: 1098-104.

[7] Brown BG, Bolson E, Frimer M, Dodge HT. Angiographic distinction between variant angina and nonvasospastic chest pain. Circulation 1978; 58: II-122.

[8] Heupler FA, Proudfit WL, Razavi M, Shirey EK, Greenstreet R, Sheldon WC. Ergonovine maleate provocative test for coronary artery spasm. Am J Cardiol 1978; 41: 631-40.

[9] Cipriano PR, Guthaner DF, Orlick AE, Ricci DR, Wexler L, Silverman JE. Effects of ergonovine maleate on coronary arterial size. Circulation 1977; 56: III-83.

[10] Gensini GG, Kelly AE, DaCosta BCB, Huntington PP. Quantitative angiography: the measurement of coronary vasomobility in the intact animal and man. Chest 1971; 60: 522-30.

[11] Endo M, Kanda I, Hosoda S, Hayashi H, Hirosawa K, Konno S. Prinzmetal's variant form of angina pectoris. Re-evaluation of mechanisms. Circulation 1975; 52: 33-7.

[12] Hosoda S, Kimura E. Efficacy of nifedipine in the variant form of angina pectoris. In: Jatene AD, Lichtlen PR, eds. 3rd Int Adalat Symp. Amsterdam: Excerpta Medica, 1976: 195-9.

[13] Antman E, Muller J. Goldberg S, et al. Nifedipine therapy for coronary artery spasm. Experience in 127 patients. N Engl J Med June 1980; 302, 23: 1269-73.

[14] Previtali M, Salerno JA, Tavazzi L, et al. Treatment of angina at rest with nifedipine: a short-term controlled study. Am J Cardiol 1980; 45: 825-30.

[15] Fleckenstein-Grün G, Fleckenstein A. CalciumAntagonismus, ein Grundprinzip der Vasodilatation. In: Fleckenstein A, Roskamm H, eds. Berlin, Heidelberg, New York: Springer Verlag, 1980: 191-207.

[16] Gunther S, Green L, Muller JE, Mudge GH, Grossmann W. Inappropriate coronary vasoconstriction in patients with coronary artery disease: a role for nifedipine? Am J Cardiol 1979; 44: 793-7.

[17] Hugenholtz PG, Verdouw PD, Meester GT. Fiberoptics in cardiac catheterization, II. Practical applications. In: Bloomfield DA, ed. Dye curves: the theory practice of indicator dilution. Baltimore, London, Tokyo: University Park Press, 1974: 285-311.

[18] Meester GT, Bernard N, Zeelenberg C, Brower RW, Hugenholtz PG. A computer system for real time analysis of cardiac catheterization. Cathet Cardiovas Diagn 1975; 1: 113-32.

[19] Meester GT, Zeelenberg C, Gorter S, Miller AC, Hugenholtz PG. Beat-to-beat analysis of left ventricular function parameters. Eur J Cardiol 1974; 1: 279 282 . 
[20] Serruys PW, Brand M v/d, Katen HJ ten, Brower RW. Regional wall motion following intra-bypass injection of nifedipine. Design of a protocol and initial experience. In: Fleckenstein A, Roskam A, eds. CalciumAntagonismus. Berlin, Heidelberg, New York: Springer Verlag, 1980: 282-92.

[21] Reiber JHC, Booman F, Tan HS, et al. A cardiac image analysis system. Objective quantitative processing of angiocardiograms. Proc Comp Cardiol, 1978: 239-42.

[22] Reiber JHC, Booman F, Tan HS, et al. Computer processing of coronary occlusions from X-ray arteriograms. Inserm 1979; 88: 79-92.

[23] Booman F, Reiber JHC, Gerbrands JJ, et al. Quantitative analysis of coronary occlusions from coronary cine-angiograms. Proc Comp Cardiol, Geneva, Sept. 26-28, 1979: 177-80.

[24] Michels R, Kint PP, Hagemeijer F, et al. Intra aortic balloon pumping in coronary artery disease. Herz 1979; 4: 397-409.

[25] Michels R, Haalebos M, Kint PP, et al. Intra aortic balloon pumping in myocardial infarction and unstable angina. Eur Heart J 1980; 1: 31-43.

[26] Leary T. Coronary spasm as a possible factor in producing sudden death. Am Heart J 1935; 10: 338-48.

[27] Eliot RS, Edwards JS. Pathology of coronary atherosclerosis and its complications. In: Hurst JW, ed. The heart, arteries and veins. 3rd ed. New York: McGrawHill, 1974: 1103-16.

[28] Klocke FJ. Coronary blood flow in man. Progress Cardiovasc Dis 1976; 19: 117-66.

[29] Serruys PW, Brand M v/d. Effects of nifedipine on left ventricular isovolumic contraction following intravenous or intracoronary administration. Circulation 1979; 59 and 60, II: 82.

[30] Serruys PW, Brower RW, Bom AH, Katen HJ ten, Hugenholtz PG. Contractility, relaxation and regional wall motion following intracoronary injection of a $\mathrm{Ca}^{++}$antagonist. Circulation 1979; 59 and 60, II: 180.

[31] Kaltenbach M, Schulz W, Kober G. Effects of nifedipine after intravenous and intracoronary administration. Am J Cardiol 1979; 44: 832-8.

[32] Gould KL. Dynamic coronary stenosis. Am J Cardiol 1980; 45: 286-92.

[33] Doerner TC, Brown GB, Bolson E, Frimer M, Dodge HT. Vasodilatory effects of nitroglycerine and nitroprusside in coronary arteries - a comparative analysis. Am J Cardiol 1979; 43: 416. (Abstract).

[34] Brand M v/d, Remme WJ, Meester GT, Tiggelaar-de Widt I, Ruiter R de, Hugenholtz PG. Changes in left and right ventricular haemodynamics in angina pectoris patients following Adalat administration in third international Adalat Symposium. In: Jatene AD, Lichtlen PR, eds. New therapy of ischemic heart disease. Amsterdam: Excerpta Medica, 1976: 69-75.
[35] Serruys PW, Brower RW, Brand M v/d, Michels R, Hugenholtz PG. Effets hémodynamiques de la nifédipine après injection intraveineuse ou intracoronarienne. Arch Mal Coeur 1980 (in press).

[36] Théroux P, Waters DD, Affaki GS, Crittin J, Bonan R, Mizgala HF. Provocative testing with ergonovine to evaluate the efficacy of treatment with calcium antagonists in variant angina. Circulation 1979; 59-60, II: 248.

[37] Chierchia S, Brunelli C, Simonetti I, Lazzari M, Maseri A. Sequence of events in angina at rest: primary reduction in coronary flow. Circulation 1980; 61: 759768.

[38] Guazzi M, Polese A, Fiorentini C, Magrini F, Olivari MT, Bartorelli C. Left and right heart haemodynamics during spontaneous angina pectoris: comparison between angina with ST-segment depression and angina with ST-segment elevation. Br Heart J 1975; 37: 401413.

[39] Chierchia S, Marchesi C, Maseri A. Evidence of angina not caused by increased myocardial metabolic demand and pattern of electrocardiographic and hemodynamic alteration during 'primary' angina. In Maseri A, Klassen GA, Lesch M, eds. Primary and secondary angina pectoris. New York: Grune and Stratton, 1978: 145.

[40] Vatner SF, Franklin D, Higgins CB, et al. Coronary dynamics in unrestrained conscious baboons. Am J Physiol 1971; 221: 1396-401.

[41] Vatner SF, Franklin D, Citters RL van, et al. Effects of carotid sinus nerve stimulation on the coronary circulation of the conscious dog. Circ Res 1970; 27 : $11-21$.

[42] Bayliss WM. On the local reactions of the arterial wall to changes in internal pressure. J Physiol 1902; 28: $220-32$.

[43] Yokoyama M, Henry PD. Responsiveness of atherosclerotic rabbit aorto to adrenergic and cholinergic stimulation. Am J Cardiol 1980; 45: 454.

[44] Berne RM, Belardinelli L, Harder DR, Sperelakis N, Rubio R. Response of large and small coronary arteries to adenosine, nitroglycerin, cardiac glycosides and calcium antagonists. In: Fleckenstein A, Roskamm H, eds. Calcium-Antagonismus. Berlin, Heidelberg, New York: Springer Verlag, 1980: 208-20.

[45] Hashimoto K, Ono H, O'Hara N. Blockade of renal autoregulatory vasoconstriction by calcium antagonists. In: Fleckenstein A, Roskamm H, eds. CalciumAntagonismus. Berlin, Heidelberg, New York: Springer Verlag, 1980: 221-9.

[46] Yasue H, Touayama M, Shimamoto M, et al. Role of autonomic nervous system in the pathogenesis of Prinzmetal's variant form of angina. Circulation 1974; 50: 534-9. 